\title{
Mechanical and Tribological Properties of Carbon-Based Graded Coatings
}

\author{
M. Kot, ${ }^{1}$ L. Major, ${ }^{2}$ J. M. Lackner, ${ }^{3}$ K. Chronowska-Przywara, ${ }^{1}$ \\ M. Janusz, ${ }^{2}$ and W. Rakowski ${ }^{1}$ \\ ${ }^{1}$ Faculty of Mechanical Engineering and Robotics, AGH University of Science and Technology, Aleja Mickiewicza 30, \\ 30-059 Krakow, Poland \\ ${ }^{2}$ Institute of Metallurgy and Materials Sciences, Polish Academy of Sciences, Ulica Reymonta 25, 30059 Krakow, Poland \\ ${ }^{3}$ Joanneum Research Forschungsges.m.b.H., Institute for Surface Technologies and Photonics, Functional Surfaces, \\ Leobner Straße 94, 8712 Niklasdorf, Austria
}

Correspondence should be addressed to M. Kot; kotmarc@agh.edu.pl

Received 13 October 2015; Revised 8 January 2016; Accepted 12 January 2016

Academic Editor: Albano Cavaleiro

Copyright ( $\odot 2016$ M. Kot et al. This is an open access article distributed under the Creative Commons Attribution License, which permits unrestricted use, distribution, and reproduction in any medium, provided the original work is properly cited.

\begin{abstract}
The paper presents research on coatings with advanced architecture, composed of a $\mathrm{Cr} / \mathrm{Cr}_{2} \mathrm{~N}$ ceramic/metal multilayer and graded carbon layers with varying properties from $\mathrm{Cr} / \mathrm{a}-\mathrm{C}: \mathrm{H}$ to a-C:N. The microstructure of the coatings was analysed using transmission electron microscopy and Energy Dispersive Spectroscopy, the mechanical properties were tested by nanoindentation, spherical indentation, and scratch testing, and tribological tests were also conducted. The proper selection of subsequent layers in graded coatings allowed high hardness and fracture resistance to be obtained as well as good adhesion to multilayers. Moreover, these coatings have higher wear resistance than single coatings and a friction coefficient equal to 0.25 .
\end{abstract}

\section{Introduction}

Thin, hard coatings deposited by physical, vacuum methods are increasingly used in almost all branches of industry. In mechanical engineering their main aim is to limit wear, thereby extending the lifetime of machine parts, and reduce friction. Coatings work in very different conditions, more and more severe; therefore, single coatings cannot fulfil all the required demands, and coatings with complex architecture have to be designed. These may be created by different materials with contrasting properties and provide results which are unobtainable for conventional metal, ceramic, and carbon coatings, which are soft and pliable or hard and brittle.

Properly selected coatings and, in many cases, pretreatment of substrates before coating can significantly increase the load-bearing capacity of surfaces or reduce the size of machine parts. Nowadays, the most commonly used PVD coatings are nitrides [1-3] and carbides [4-6] of transition metals and carbon-based coatings [7-11]. The former are hard and rigid (hardness $H=15-40 \mathrm{GPa}$, elasticity modulus $E=$ 200-500 GPa), and their wear resistance may be many times better than steel and titanium alloy substrates. However, their coefficients of friction $(\mathrm{CoF})$ in dry conditions are within the $0.2-0.5$ range. This parameter is lower for carbon coatings and $\mathrm{CoF}=0.01-0.1$ is usually presented in the literature $[12,13]$. Their excellent tribological properties are discussed in [14]. The main mechanism responsible for such properties is the graphitization process during which a thin graphite tribolayer, with very low shear strength, is created on the surface $[15,16]$. In vacuum and lack of moisture, an important role in the friction process is played by hydrogen [17] contained in the a-C:H coatings, by shielding sigma bonds. However, both ceramic and carbon materials are prone to fracture, and their fracture toughness $K_{1 \mathrm{C}}$ is not higher than $5 \mathrm{MPa} \cdot \mathrm{m}^{1 / 2}[17,18]$. Hence, it is necessary to provide adequate support for these coatings, because even small deformations of coating-substrate systems can lead to coating fracture. This is the main application problem for coatings deposited on soft substrates, such as steel and titanium alloys. A possible solution is substrate hardening prior to coating deposition by heat or chemical treatment, 
TABLE 1: Summary of the mechanical and tribological properties of single coatings and the substrate.

\begin{tabular}{|c|c|c|c|c|}
\hline Material & $H^{*}[\mathrm{GPa}]$ & $E^{*}[\mathrm{GPa}]$ & $\mathrm{CoF}^{* *}$ & $W_{V}^{* *} 10^{-6}\left[\mathrm{~mm}^{3} / \mathrm{Nm}\right]$ \\
\hline Steel substrate AISI 304 & 4 & 190 & 0.5 & 560 \\
\hline $\mathrm{Cr}$ & 8 & 180 & 0.7 & 200 \\
\hline $\mathrm{Cr} / \mathrm{Cr}_{2} \mathrm{~N}$ & 15.7 & 228 & 0.5 & 3.9 \\
\hline $\mathrm{Cr} / \mathrm{a}-\mathrm{C}: \mathrm{H}$ & 18.4 & 280 & 0.4 & 2.2 \\
\hline $\mathrm{Cr} / \mathrm{a}-\mathrm{C}: \mathrm{H}, \mathrm{N}$ & 15.7 & 143 & 0.22 & 0.65 \\
\hline $\mathrm{a}-\mathrm{C}: \mathrm{N}$ & 12 & 120 & 0.1 & 3.8 \\
\hline
\end{tabular}

${ }^{*}$ Results of nanoindentation tests (Berkovich indenter, $2 \mathrm{mN}$ max. load)

${ }^{* *}$ Results of tribological tests (ball-on-disc, $6 \mathrm{~mm} \mathrm{Al}_{2} \mathrm{O}_{3}$ ball, $1 \mathrm{~N}$ load).

such as glow discharge nitriding $[19,20]$ or ion implantation $[21,22]$, which of course increases total production costs due to the performance of additional operations. After such treatments, in many cases, further surface polishing prior to the deposition of thin PVD coatings must be carried out. Therefore, it is advisable to design appropriate complex coating produced in one vacuum process. However, this requires the deposition of many sublayers with significantly different properties within one coating to ensure good adhesion to the substrate, low residual stresses, adequate load capacity, low friction and wear, and high resistance to environmental factors. Coatings built in this manner that provide small changes in the mechanical properties of successive layers are called graded coatings [23, 24].

The paper presents the research results of the microstructure and mechanical tests of coatings with a complex microstructure, designed as low-wear and low-friction coatings. The studies of single coatings that were applied in the tested complex coatings have been shown in previous works:

(i) $\mathrm{Cr} / \mathrm{CrN}$ multilayers [25].

(ii) Cr/a-C:H nanocomposite coatings [26].

(iii) a-C:H, a-C:N hydrogenated and nitrogenated carbon coatings [27].

The main aims were to deposit coatings with predesigned, advanced architecture by magnetron sputtering on an AISI 304 austenitic steel substrate, characterizing their mechanical (nanohardness, Young's modulus, adhesion to the substrate, and fracture toughness) and tribological (wear resistance, coefficient of friction) properties that exceed the properties of the single coatings forming the proposed coatings.

\section{Tested Coatings}

Coatings were deposited by an unbalanced magnetron sputtering method with a $-50 \mathrm{~V}$ bias. Two oppositely arranged rectangular sputter magnetrons, equipped with chromium and graphite targets (Schunk Elektrokohle, Bad Goisern, Austria), were used. Mirror-polished AISI 304 austenitic steel substrates were coated. Prior to deposition, the substrates in the form of $20 \times 20 \times 2$ plates were cleaned in an industrial washing machine (Miele Professional IR 6002, Guetersloh, Germany) with surface active agents, dried, and mounted on a $3 \mathrm{D}$ rotatable planetary table in industrial-like R\&D deposition equipment (Leybold Univex 450 machine,
Leybold Vakuum, Cologne, Germany, equipped with a cubelike chamber of $0.5 \mathrm{~m}^{3}$ volume). After pumping to high vacuum conditions $\left(2 \times 10^{-5} \mathrm{mbar}\right)$, the ion plasma treatment was performed at room temperature. Therefore, a linear anode layer ion source (Veeco ALS 340, Fort Collins, CO, USA) operated between 1 and $3 \mathrm{keV}$ acceleration voltage, with oxygen-argon gas mixtures, was used.

$16 \mathrm{xCr} / \mathrm{Cr}_{2} \mathrm{~N}$ multilayers and then gradient carbon coatings were deposited on steel substrates. The microstructure of carbon layers changed from a $\mathrm{Cr} / \mathrm{a}-\mathrm{C}: \mathrm{H}$ nanocomposite layer, through $\mathrm{Cr} / \mathrm{a}-\mathrm{C}: \mathrm{H}, \mathrm{N}$, to nitrogenated a-C:N on the surface. The subsequent layers in the carbon coating were also deposited previously as single layers, as well as multilayers, and tested. Their mechanical properties, shown as the results of indentation tests (nanohardness $H$ and elasticity modulus $E$ ) and tribological tests (coefficient of friction $\mathrm{CoF}$ and wear index $W_{V}$ ), are summarized in Table 1 . The methodology and parameters of these tests were the same as those used during studies of the proposed coating and are described below in the Experiment section.

Ceramic/metal $16 x \mathrm{Cr} / \mathrm{Cr}_{2} \mathrm{~N}$ multilayers have a $250 \mathrm{~nm}$ bilayer period (the sum of the thickness of two successive $\mathrm{Cr}$ and $\mathrm{Cr}_{2} \mathrm{~N}$ layers). The sixteen bilayers in the multilayer give a total thickness of $4 \mu \mathrm{m}$. The thickness of $\mathrm{Cr}$ metal layers is two times lower than $\mathrm{Cr}_{2} \mathrm{~N}$ nitride layers $\left(\mathrm{Cr}-83 \mathrm{~nm}, \mathrm{Cr}_{2} \mathrm{~N}\right.$ $167 \mathrm{~nm}$ ) and this $\mathrm{Cr}: \mathrm{Cr}_{2} \mathrm{~N}=1: 2$ ratio was chosen based on previous studies of ceramic/metal multilayer coatings [28]. The changes in the mechanical properties of such multilayers with a different metal to ceramic layer thickness ratio, in the case of $\mathrm{Al} / \mathrm{AlN}$ materials, were also presented in [29]. A $\mathrm{Cr} / \mathrm{Cr}_{2} \mathrm{~N}$ multilayer, instead of a $\mathrm{CrN}$ single coating, was deposited for two reasons. Firstly, it is applied directly on a steel substrate and its significantly lower elasticity modulus than that of a CrN coating, closer to the modulus of steel as well as to carbon layers that are applied on them, is highly favourable. Such a small mismatch of this parameter indicates small shear stress in the coating-substrate interface and thus shows its high strength, which was confirmed by scratch testing [30]. However, a multilayer is almost 4 times harder than uncoated steel. Secondly, the fracture resistance of ceramic/metal multilayers is much higher than single ceramic coatings [31, 32]. So, if a crack appears in the multilayer, it is not as readily transferred to the outer carbon layer as in the case of a single ceramic layer.

Afterwards, $1 \mu \mathrm{m}$ thick graded carbon coatings (three coating types: A, B, and C), were deposited with architectures 
TABLE 2: Deposition parameters of carbon graded coatings.

\begin{tabular}{|c|c|c|c|c|c|c|c|}
\hline Step & $\begin{array}{c}\mathrm{Cr} \\
{[\mathrm{W}]}\end{array}$ & $\begin{array}{c}\mathrm{C} \\
{[\mathrm{W}]}\end{array}$ & $\begin{array}{c}\mathrm{C}_{2} \mathrm{H}_{2} \\
{[\mathrm{sccm}]}\end{array}$ & $\begin{array}{c}\mathrm{Ar} \\
{[\mathrm{sccm}]}\end{array}$ & $\begin{array}{c}\mathrm{N}_{2} \\
{[\mathrm{sccm}]}\end{array}$ & $\begin{array}{l}\text { Time } \\
{[\mathrm{min}]}\end{array}$ & $\begin{array}{c}\text { Thickness } \\
{[\mathrm{nm}]}\end{array}$ \\
\hline \multicolumn{8}{|c|}{ Version A } \\
\hline 1 & 1400 & 50 & 5 & 45 & 0 & 14 & \\
\hline 2 & 1230 & 410 & 4.4 & 45.6 & 0 & 14 & 270 \\
\hline 3 & 1060 & 780 & 3.8 & 46.2 & 0 & 14 & \\
\hline 4 & 890 & 1150 & 3.1 & 45.2 & 1.7 & 14 & \multirow{6}{*}{530} \\
\hline 5 & 720 & 1520 & 2.5 & 44.2 & 3.3 & 14 & \\
\hline 6 & 550 & 1890 & 1.9 & 43.1 & 5.0 & 14 & \\
\hline 7 & 380 & 2260 & 1.3 & 42 & 6.7 & 14 & \\
\hline 8 & 210 & 2630 & 0.6 & 41.1 & 8.3 & 14 & \\
\hline 9 & 50 & 3000 & 0 & 40 & 10.0 & 14 & \\
\hline 10 & 0 & 3000 & 0 & 40 & 10.0 & 30 & 200 \\
\hline \multicolumn{8}{|c|}{ Version B } \\
\hline 1 & 1400 & 50 & 5 & 45 & 0 & 14 & \\
\hline 2 & 1230 & 410 & 4.4 & 45.6 & 0 & 14 & \\
\hline 3 & 1060 & 780 & 3.8 & 46.2 & 0 & 14 & \\
\hline 4 & 890 & 1150 & 3.1 & 46.9 & 0 & 14 & 530 \\
\hline 5 & 720 & 1520 & 2.5 & 47.5 & 0 & 14 & \\
\hline 6 & 550 & 1890 & 1.9 & 48.1 & 0 & 14 & \\
\hline 7 & 380 & 2260 & 1.3 & 45.4 & 3.3 & 14 & \\
\hline 8 & 210 & 2630 & 0.6 & 42.7 & 6.7 & 14 & 270 \\
\hline 9 & 50 & 3000 & 0 & 40 & 10.0 & 14 & \\
\hline 10 & 0 & 3000 & 0 & 40 & 10 & 30 & 200 \\
\hline \multicolumn{8}{|c|}{ Version C } \\
\hline 1 & 1400 & 50 & 20 & 30 & 0 & 14 & \\
\hline 2 & 1230 & 410 & 22.5 & 27.5 & 0 & 14 & \\
\hline 3 & 1060 & 780 & 25 & 25 & 0 & 14 & \\
\hline 4 & 890 & 1150 & 27.5 & 22.5 & 0 & 14 & 530 \\
\hline 5 & 720 & 1520 & 30 & 20 & 0 & 14 & \\
\hline 6 & 550 & 1890 & 32.5 & 18.5 & 0 & 14 & \\
\hline 7 & 380 & 2260 & 35 & 11.7 & 3.3 & 14 & \\
\hline 8 & 210 & 2630 & 37.5 & 5.8 & 6.7 & 14 & 270 \\
\hline 9 & 50 & 3000 & 40 & 0 & 10.0 & 14 & \\
\hline 10 & 0 & 3000 & 0 & 40 & 10 & 30 & 200 \\
\hline
\end{tabular}

as given in Table 2. The deposition process was led from the two $\mathrm{Cr}$ and $\mathrm{C}$ targets. Gradient layers were realized by stepwise changes of power and $\mathrm{C}_{2} \mathrm{H}_{2}, \mathrm{Ar}$, and $\mathrm{N}_{2}$ gas flow conditions (Table 2). Firstly, on the multilayer, a load-bearing $\mathrm{Cr} / \mathrm{a}-\mathrm{C}: \mathrm{H}$ nanocomposite layer, with the highest hardness and modulus of elasticity (Table 1), was applied. In the second stage, the properties of coatings were stepwise changed to lower the hardness and stiffness of $\mathrm{Cr} / \mathrm{a}-\mathrm{C}: \mathrm{H}, \mathrm{N}$ by changing the atmosphere in the chamber-an increase in $\mathrm{N}_{2}$ gas flow. Simultaneously, the power of the magnetron on the Cr target was reduced.

These Cr/a-C:H,N layers have significantly better tribological properties, the smallest wear and $\mathrm{CoF}=0.2$. The elasticity modulus is also low and, favourably, is similar to the elasticity modulus of a-C:N, deposited as the outermost layer.
These nitrogenated carbon layers exhibit the lowest $\mathrm{CoF}=0.1$, although the wear index is higher than in the $\mathrm{Cr} / \mathrm{a}-\mathrm{C}: \mathrm{H}$ and $\mathrm{Cr} / \mathrm{a}-\mathrm{C}: \mathrm{H}, \mathrm{N}$ nanocomposite layers.

The main difference between coatings $\mathrm{A}$ and $\mathrm{B}$ is the thickness of the load-bearing part of the coating that consists of the $\mathrm{Cr} / \mathrm{a}-\mathrm{C}: \mathrm{H}$ nanocomposite layer. In version $\mathrm{A}$, this layer is $270 \mathrm{~nm}$ thick, while through the next $530 \mathrm{~nm}$ the rising nitrogen flow introduced into the chamber causes a gradual reduction in hardness and rigidity to the characteristic values of an a-C:H,N coating. On the contrary, version $B$ has reverse layer thickness: rigid $530 \mathrm{~nm}$ and graded $270 \mathrm{~nm}$. In contrast, version $\mathrm{C}$ was chosen to be more polymeric (higher $H$ content) by deposition in a higher $\mathrm{C}_{2} \mathrm{H}_{2}$ gas flow. The properties and structure analysis of such soft polymeric-like carbon coatings were presented in $[33,34]$. 


\section{Experimental}

The coatings' microstructures were analysed by transmission electron microscopy (TEM) using a Tecnai G ${ }^{2}$ F20 $200 \mathrm{kV}$ (FEG) microscope on thin foils prepared by the focus ion beam (FIB) technique. Mechanical properties were studied by the nanoindentation technique $[35,36]$ using a CSM nanoindenter. Tests were performed with a Berkovich geometry diamond at 2 and $5 \mathrm{mN}$ maximum load and 4 and $10 \mathrm{mN} / \mathrm{min}$ loading and unloading rates, respectively. The Oliver and Pharr procedure was used for hardness and elasticity modulus calculation [37]. On each coating and each load, at least 10 indentations were made, while mean values and standard deviation values were taken for further analysis. Indentations at higher load, $1 \mathrm{~N}$, allows analysis of the coatings' fracture resistance to be performed. The values of maximum load to the first crack event and corresponding penetration depth were compared. It was not possible to calculate the fracture toughness $K_{\text {IC }}$ according to equations cited in the literature, like $\mathrm{Li}$ and Bhushan [38], because of the complex coating architecture that results in complex stress distribution and stiffness of subsequent layers. To study the load-bearing capacity of the three tested coatings, spherical indentations were performed with a $20 \mu \mathrm{m}$ tip radius diamond under a $500 \mathrm{mN}$ maximal load. The loadpenetration depth curves were transformed into stress-strain curves according to the procedure presented in previous papers [37]. The first coating crack corresponds to pop-ins on indentation curves and sudden drops in stress on stress-strain curves [39]. This deformation limit, as an area under the curve up to the coating fracture, was calculated and called the apparent fracture toughness $K^{\prime}$ [40]. This parameter provides important information on the load-bearing capacity of the coating-substrate system. Scratch testing [30, 41] with an MCT CSM apparatus and a standard conical Rockwell C indenter with a $200 \mu \mathrm{m}$ tip radius was mainly used to study the adhesion of carbon graded coatings to multilayers. Tests were performed within the $0-30 \mathrm{~N}$ load range, along a $5 \mathrm{~mm}$ scratch length and $5 \mathrm{~mm} / \mathrm{min}$ scratch speed. According to the ISO standard [30], the critical loads $L_{\mathrm{C} 1}$ and $L_{\mathrm{C} 2}$, which correspond to cohesive and adhesive failures of the coating, were determined. The tribological properties of coatingsubstrate systems were studied with a ball-on-disc tribometer [42] at two different loads of 1 and $5 \mathrm{~N}$. Assuming contact with an infinitely thick coating and $6 \mathrm{~mm}$ diameter $\mathrm{Al}_{2} \mathrm{O}_{3}$ ball, contact stresses calculated using the Hertz equation $[43,44]$ were 0.45 and $0.8 \mathrm{GPa}$, respectively. Being careful to conduct tests only with wear track depth within the coating, the total cycle numbers were 5000 for the $5 \mathrm{~N}$ load and 20000 cycles for $1 \mathrm{~N}$. For both tests, sliding speed was $0.05 \mathrm{~m} / \mathrm{s}$. During the tests, friction force was recorded, which allowed changes in the friction coefficient to be observed. Wear track profiles and ball scars were measured after tests by a stylus profilometer (coatings) and through light microscopy observations (balls), and then the wear index $W_{V}$ was calculated using the formula [42]

$$
W_{V}=\frac{V}{F_{n} \cdot s},
$$

where $V$ is volume of removed material, $F_{n}$ is normal load, and $s$ is length of the wear track.

\section{Results and Discussion}

Figures 1 and 2 show the microstructure of coating A. TEM observations revealed a complex coating microstructure consisting of multilayer coating and graded carbon coating (Figure 1(a)). In the case of the $\mathrm{Cr} / \mathrm{Cr}_{2} \mathrm{~N}$ multilayer, in many areas there is the same diffraction contrast through the interfaces. This demonstrates the strong crystallographic relation between the $\mathrm{Cr}$ and $\mathrm{Cr}_{2} \mathrm{~N}$ layers (Figure 1(b)). The presence of the $\mathrm{Cr}$ and $\mathrm{Cr}_{2} \mathrm{~N}$ layers was confirmed by electron diffraction spectroscopy performed in order to analyse the phase composition of the layers (Figures 1(c) and 1(d)).

The carbon layer deposited on the multilayer is clearly seen in Figure 2(a). Figure 2(b) shows the results of the element analysis carried out along the line marked in Figure 2(a). Within the graded carbon layer, a gradient increase in the chromium content confirms the evolution form hydrogenated carbon a-C:H (higher intensity of carbon atoms) on the surface to $\mathrm{Cr} / \mathrm{a}-\mathrm{C}: \mathrm{H}$ nanocomposite layers close to the multilayer.

Indentation test results are shown in Figures 3(a) and 3(b). The dashed lines correspond to values measured for the single coatings described above them. The hardness of coatings A and B is similar: $H=14-15 \mathrm{GPa}$. This is significantly higher than the hardness of a hydrogenated amorphous carbon a-C:H single coating (Table 1). However, it should be noted that, even at a lower load of $2 \mathrm{mN}$, the penetration depth for coatings A and B reached 90-100 nm, which indicates that the material is deformed below indentation to a depth of about $1 \mu \mathrm{m}$, assuming the commonly accepted $1 / 10$ th rule of indentation depth to radius of the deformed zone $[36,45]$. Therefore, the test results are affected by the whole graded carbon coating, including the nanocomposite coating of $\mathrm{Cr} / \mathrm{a}-\mathrm{C}: \mathrm{H}$ with a hardness above $18 \mathrm{GPa}$. Therefore, the obtained coatings are harder than a-C:N and a-C:H,N single coatings, but softer compared with the Cr/a-C:H nanocomposite coating. Similar relations were also found in the case of the elasticity modulus.

Significantly lower hardness, $H=4.7 \mathrm{GPa}$, is exhibited by coating C, but Young's modulus of $E=42 \mathrm{GPa}$, compared with coatings $A$ and $B$ with $E=150 \mathrm{GPa}$, is also much lower. This is due to the more polymeric nature (higher $H$ content) of coating $\mathrm{C}$. The hardness reduction together with a rise in the $H$ amount was also discussed in [46]. Tests with a Berkovich indenter were also performed at higher loads that allow the comparison of the fracture toughness of the tested coatings. Figure 4 presents the indentation curves performed at a $1 \mathrm{~N}$ maximum load.

The curves for coatings A and B, with almost the same hardness and elasticity modulus, were very similar except for the load level at which the first pop-in corresponding to the first edge cracks appeared. The first crack was found at $180 \mathrm{mN}$ for coating B, while coating A survived up to $330 \mathrm{mN}$. The further rise in load leads to a high stress concentration at a certain distance from the contact area. This phenomenon 


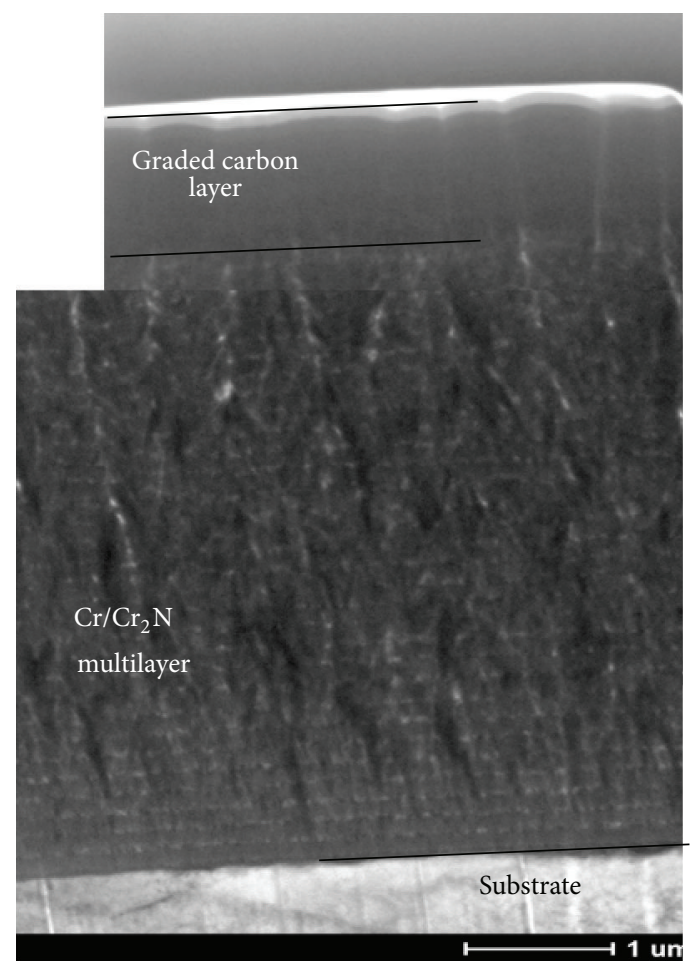

(a)

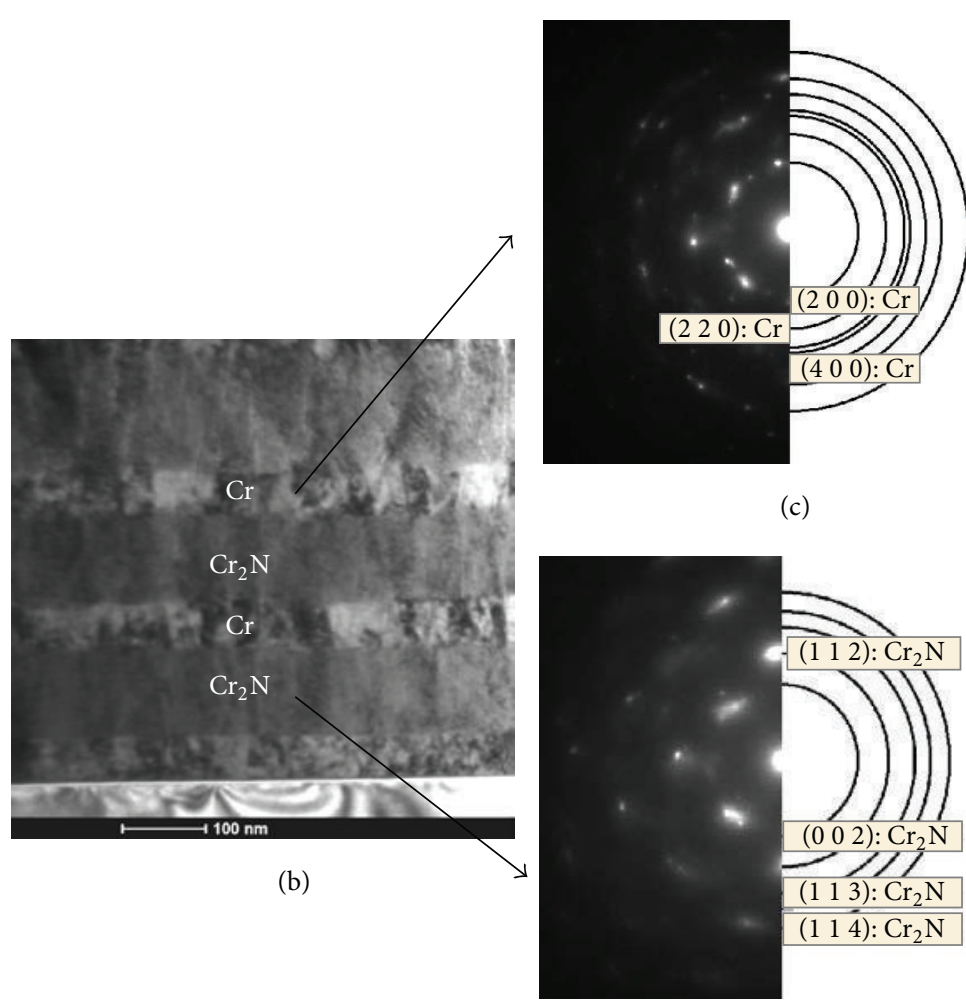

(d)

FIGURE 1: Analysis results of coating microstructure carried out using the TEM technique; (a) observation in a bright field, (b) higher magnification on the multilayer area, and $(c, d)$ analysis of the phase composition performed using electron diffraction.

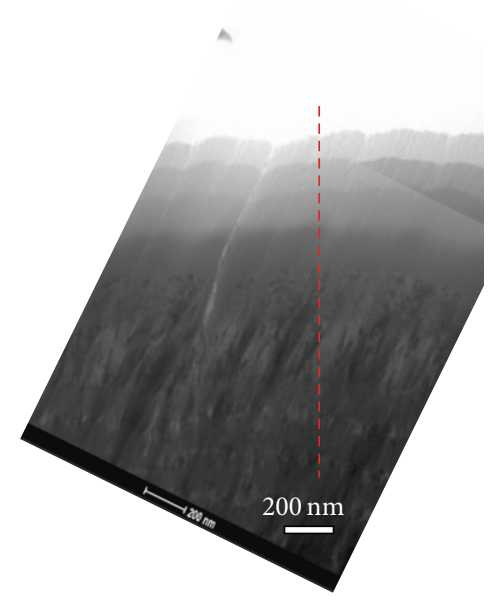

(a)

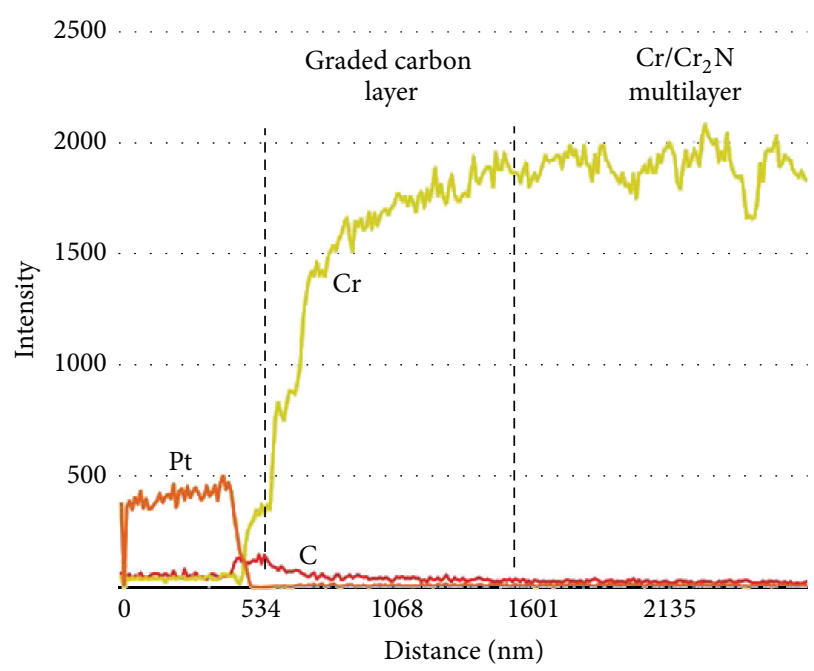

(b)

FIGURE 2: Qualitative EDS analysis of the chemical composition: (a) bright field TEM image with a pointed line of EDS analysis and (b) distribution diagram of selected elements.

was analysed based on FEM modelling results and is shown in publications $[47,48]$. If this stress exceeds the coating strength, circular cracks are formed around the imprint. These cracks appeared for coatings A and B at 1000 and $1300 \mathrm{mN}$, respectively (Figure 5(a)). But it should be pointed out that both of these coatings cracked at a much higher load than the pure carbon coatings a-C:N and a-C:H, for which significant cracks were formed at a $200-300 \mathrm{mN}$ load. These results clearly indicate the enhancement in the fracture resistance of graded coatings. Furthermore, at a load of about 


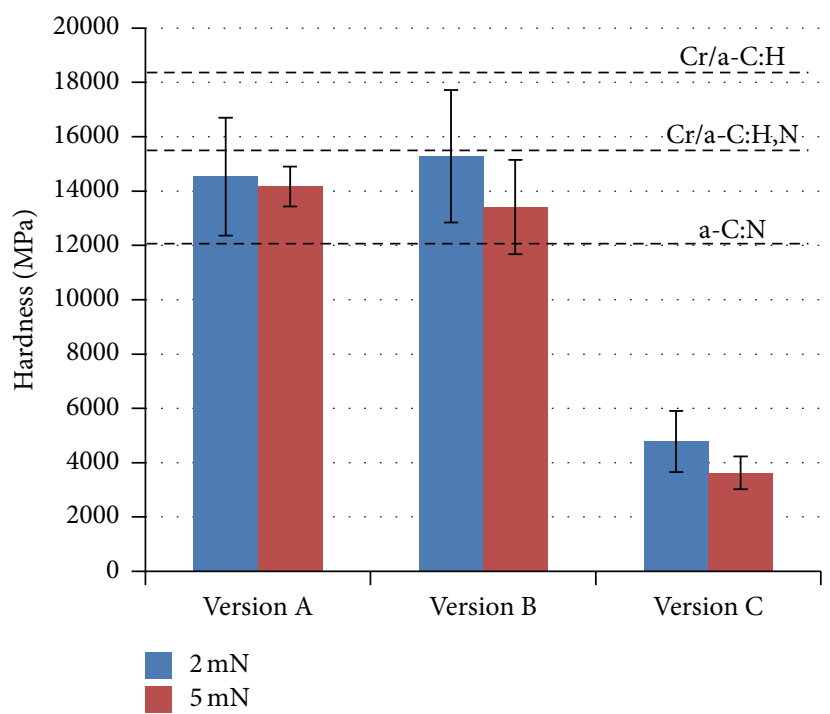

(a)

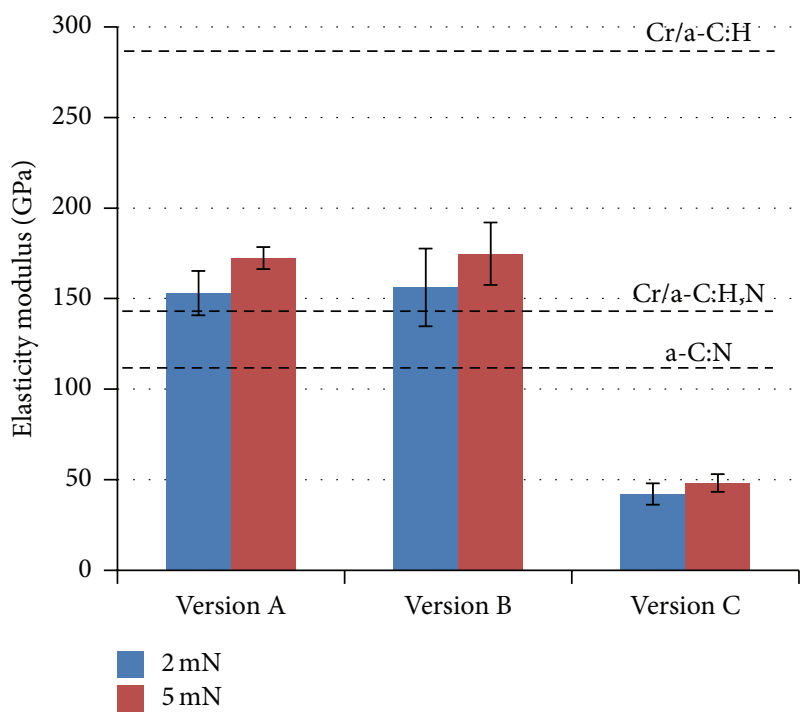

(b)

FIGURE 3: Indentation test results: (a) nanohardness and (b) elasticity modulus.

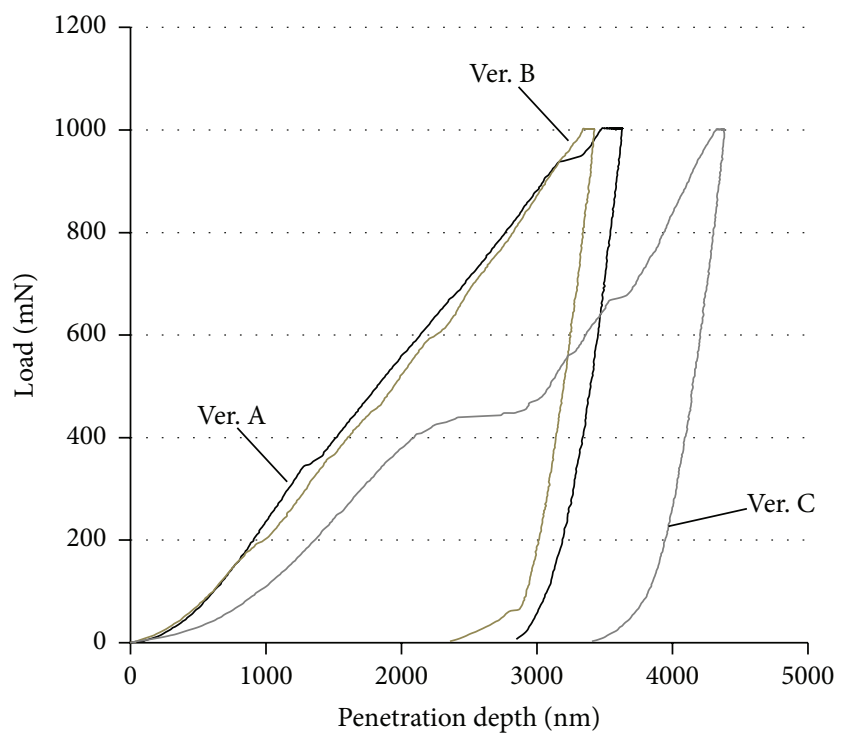

Figure 4: Berkovich indentation curves of tested coatings.

$1 \mathrm{~N}$, the failure of total single carbon coatings, in the form of large area delamination, was observed.

The images of indents for all tested coatings are shown in Figures 5(b)-5(d). The results for coating $C$ differ from the others. Initially, the load induces a much larger deformation than for coatings $\mathrm{A}$ and $\mathrm{B}$, which is clearly seen on the indentation curve. This is a result of its lower stiffness. At $400 \mathrm{mN}$, large adhesive cracks were formed (Figure 5(d)). This indicates that coating $\mathrm{C}$, despite its lower hardness and elasticity modulus, is not more fracture resistant, but quite the contrary. Indentation tests are easier for quantitative analysis when spherical indenters with a known tip radius (in this work, indenter $R=20 \mu \mathrm{m}$ ) are used [40]. The results of spherical indentations are shown in Figure 6(a) and confirm the similar mechanical properties of coatings $\mathrm{A}$ and $\mathrm{B}$, and the much lower stiffness of coating C. Cracks in coatings A and B appeared at loads of 340 and $310 \mathrm{mN}$, with the corresponding penetration depth of $600 \mathrm{~nm}$ (Figure 6(b)). A single a-C:H coating deposited on the same multilayer cracked under a $120 \mathrm{mN}$ load. For the softest coating, version C, the first fracture appeared at $440 \mathrm{mN}$ and $1200 \mathrm{~nm}$ penetration depth.

Coating $\mathrm{C}$, due to its lower elasticity modulus, is not subject to such a high tensile stress concentration as more rigid coatings. This is a result of lower contact stress in the contact area of the indenter and coating. This was confirmed by analysis of mean contact stress using the transformation procedure of indentation curves onto stress-strain curves, described in detail in previous publications [49]. The maximums of mean contact stress during spherical indentation (Figure $7(\mathrm{a})$ ) for coating $\mathrm{C}$ reached $4 \mathrm{GPa}$, while for coatings $A$ and $B$ they were higher, 7.7 and $7 \mathrm{GPa}$, respectively. Further deformation leads to a high concentration of tensile stress usually just outside the contact area and to coating fracture which can be seen as sudden drops in stress values (Figure 7(a)).

Images of circumferential cracks on coating surfaces are shown in Figures $8(a)-8(c)$. The most clearly visible crack some distance from the contact zone is on the surface of coating A. Similarly to Berkovich indentation, the fracture of coating B after spherical indentation is not as drastic as for coating A. Probably this is a result of the significantly thicker, $530 \mathrm{~nm}$ hard, load-bearing nanocomposite layer in coating B, while coating A has such a layer which is only $270 \mathrm{~nm}$ thick. Cracks on the thicker, brittle layer are more prominent and wider. Meanwhile, the value of apparent fracture toughness $K^{\prime}$ decreased slightly for the subsequent coatings $\mathrm{A}, \mathrm{B}$, and $\mathrm{C}$ (Figure 7(b)). Although coating $\mathrm{C}$ is the most flexible, the lowest value of the parameter $K^{\prime}$ derives from low pressure in the contact zone, which indicates the lowest value of 


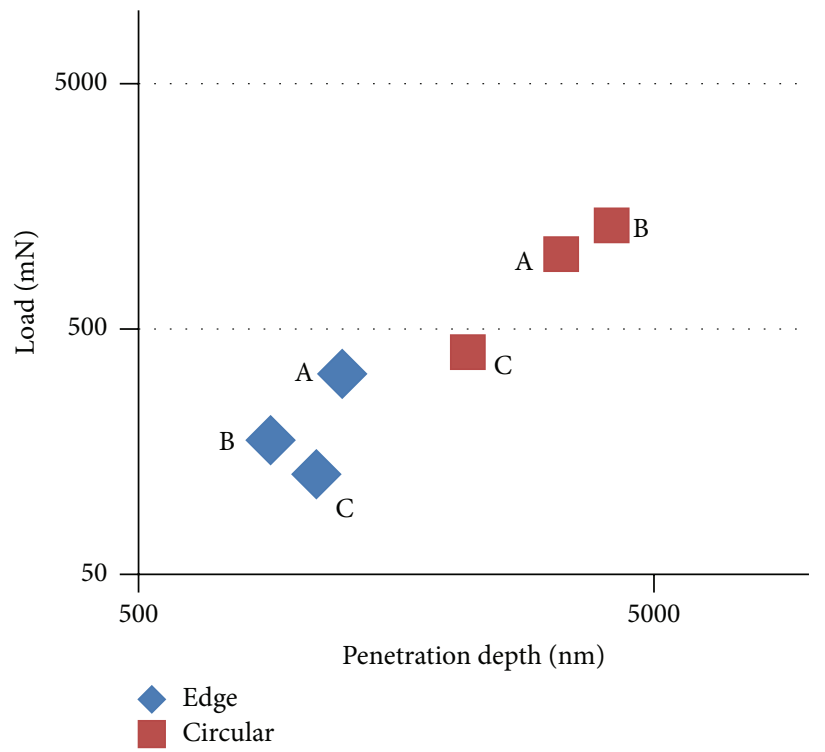

(a)

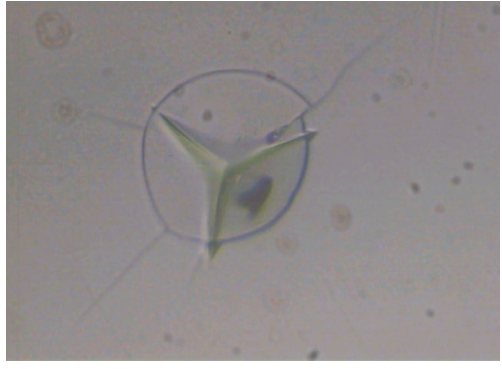

(b)

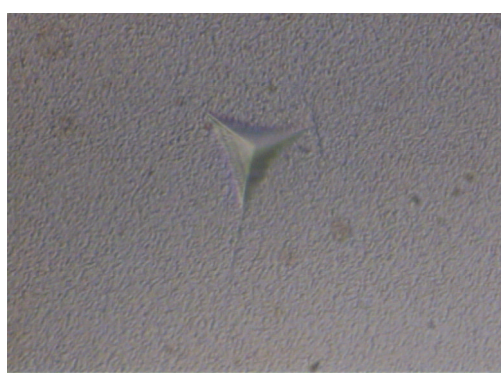

(c)

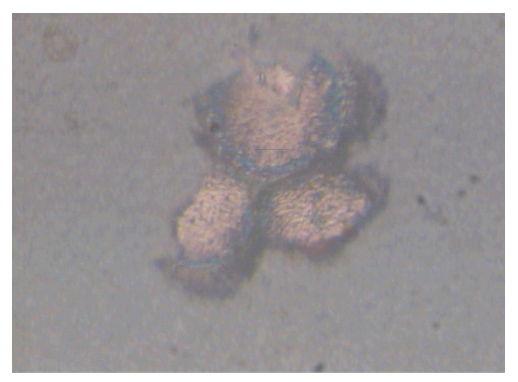

(d)

FIGURE 5: Results of indentation tests: (a) load values lead to edge and circular cracks and (b)-(d) images of indents on coatings A, B, and C, respectively.

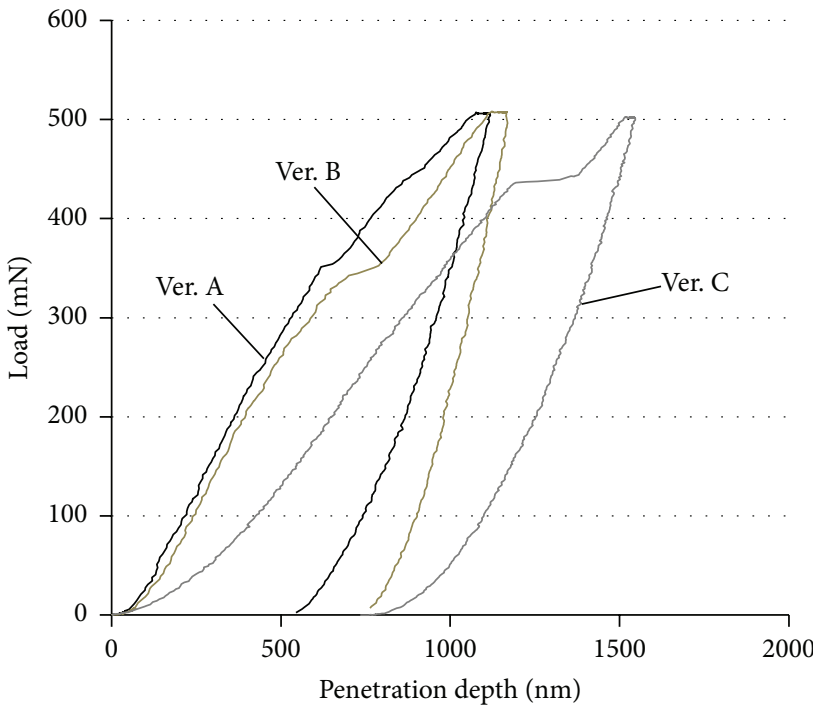

(a)

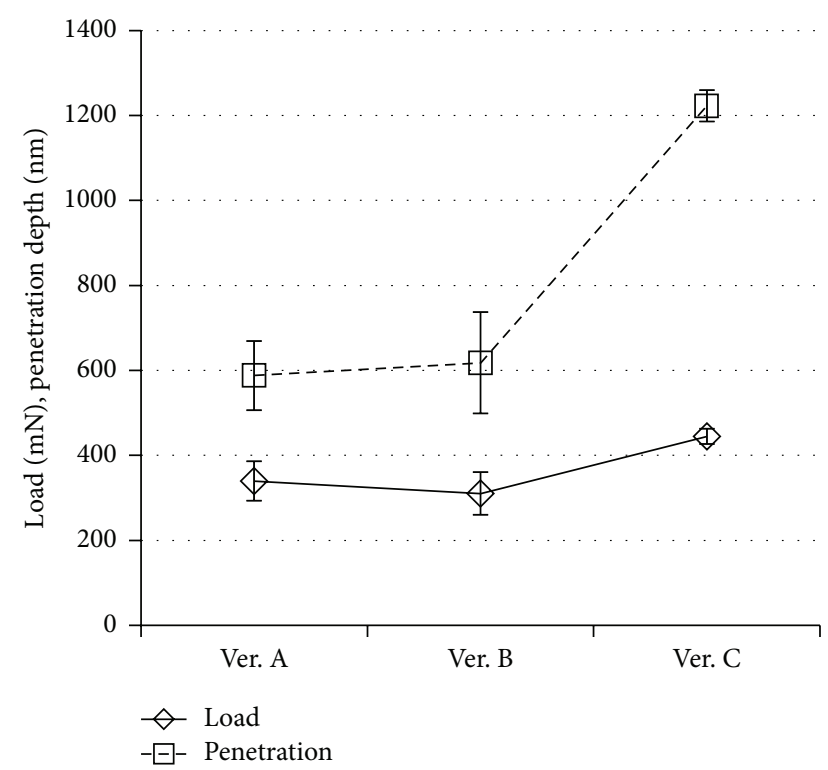

(b)

FIGURE 6: Results of spherical indentation tests: (a) indentation curves and (b) load and penetration depth that causes the first fracture. 


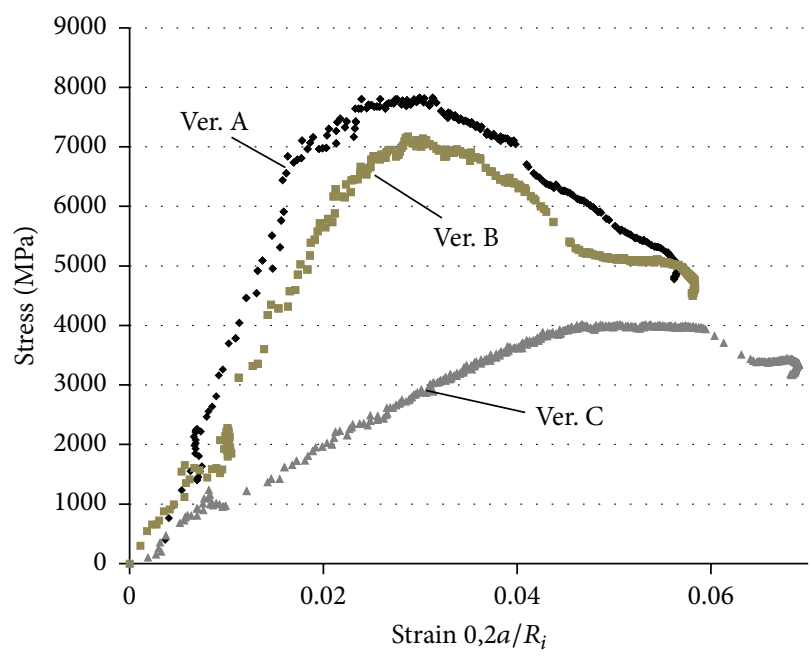

(a)

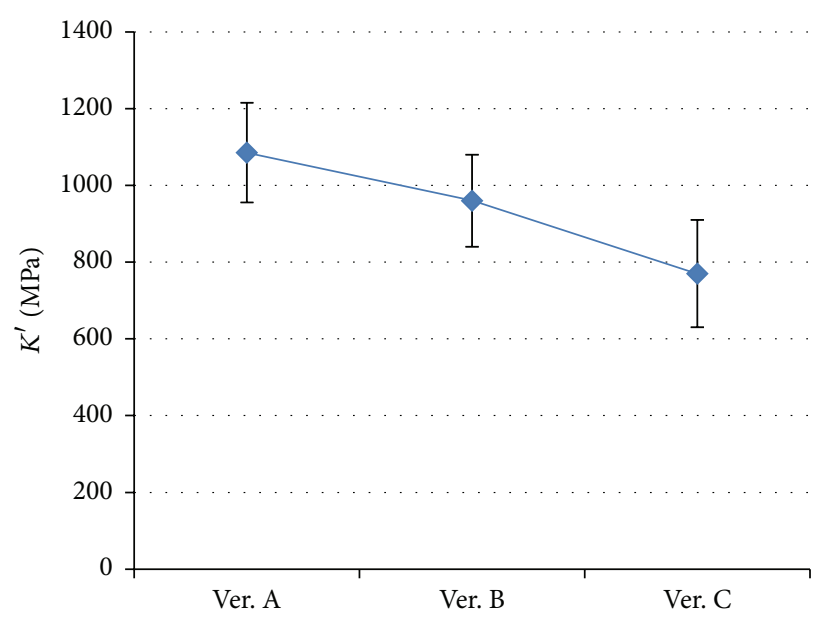

(b)

FIGURE 7: Spherical indentation results: (a) stress-strain curves and (b) apparent fracture toughness.

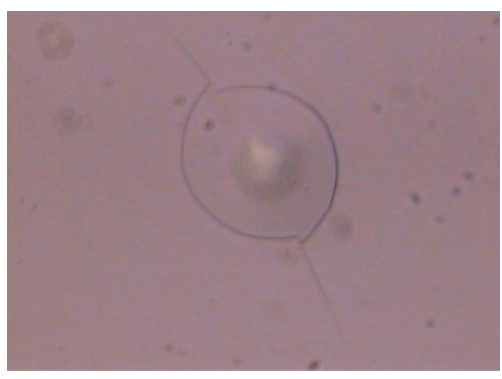

(a)

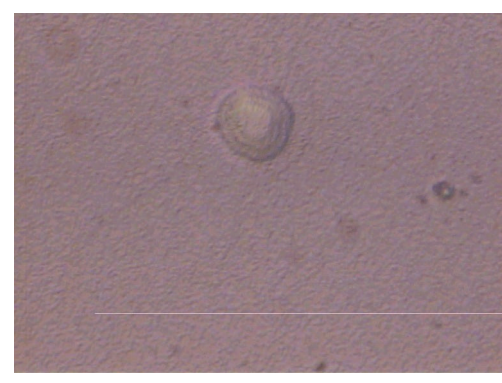

(b)

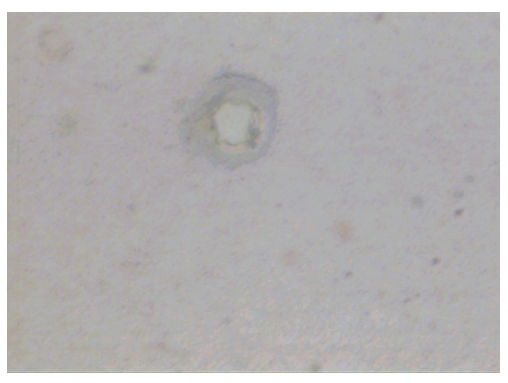

(c)

FIGURE 8: Images of coating surfaces after spherical indentations: (a) version A, (b) version B, and (c) version C.

tensile stress leading to crack formation. However, it should be noted that this analysis does not take into account the state of residual stresses that can be up to several GPa in carbon coatings [50]. Cracks on the tested coating-substrate systems were also analysed by the TEM technique on their cross-sections. For the outermost graded carbon coatings, significant differences between them were not observed.

The authors expected effective crack closing in $\mathrm{Cr} / \mathrm{Cr}_{2} \mathrm{~N}$ multilayers. The deformation mechanism of the same type of $\mathrm{Ti} / \mathrm{TiN}$ ceramic/metal multilayers was presented in previous articles $[28,34]$. Subsequent metal layers with appropriate thickness caused crack closure or at least impeded easy crack propagation through ceramic layers. $\mathrm{Cr} / \mathrm{Cr}_{2} \mathrm{~N}$ multilayers were deposited with an increased ratio of ceramic phase which, with adequate thickness of metal layers, makes it possible to significantly improve the mechanical properties of multilayers compared to multilayers with a 1:1 ratio. When the ratio of metal/ceramic layers thickness is $1: 2$, multilayers are harder and more wear resistant, but still retain a high resistance to fracture. But a further increase up to $1: 4$ causes the deterioration of fracture resistance, because the metal layers are too thin and are not able to stop the cracks propagating in the ceramic layers [51]. The mechanism of crack deflection in the $\mathrm{Cr} / \mathrm{Cr}_{2} \mathrm{~N}$ multilayer by the plastic deformation of $\mathrm{Cr}$ layers is shown in Figure 9. For the $\mathrm{Cr}$ layers, slip planes with a $45^{\circ}$ angle to cracks propagating in $\mathrm{Cr}_{2} \mathrm{~N}$ layers are visible.

Scratch test results clearly exhibited the best adhesion of coating A to the $\mathrm{Cr} / \mathrm{Cr}_{2} \mathrm{~N}$ multilayers. For that coating, no adhesive cracks were observed up to the maximum applied load, $30 \mathrm{~N}$ (Figures 10(b) and 10(c)). Meanwhile, the first cohesive cracks for all tested coatings were formed at a 1.5-1.7 N load range (Figures 10(a), 10(d), and 10(g)). The adhesion of coating $B$ was significantly weaker than that of coating $\mathrm{A}$, which was indicated by the large delaminations that appeared at a low $4 \mathrm{~N}$ load (Figures 10(e) and 10(f)). Taking into account the similar mechanical properties of both coatings A and B, the parameter that can explain that fact is the much higher residual stresses in coating $B$. This may be the result of a significantly thicker hard $\mathrm{Cr} / \mathrm{a}-\mathrm{C}: \mathrm{H}$ layer with an elasticity modulus much greater than the multilayer. The higher Young's modulus mismatch of coating and substrate and higher coating thickness lead to a higher concentration of shear stresses in the coating-substrate interface. For comparison, the single a-C:H and a-C:N coatings were removed from substrates at a $3-5 \mathrm{~N}$ load. 

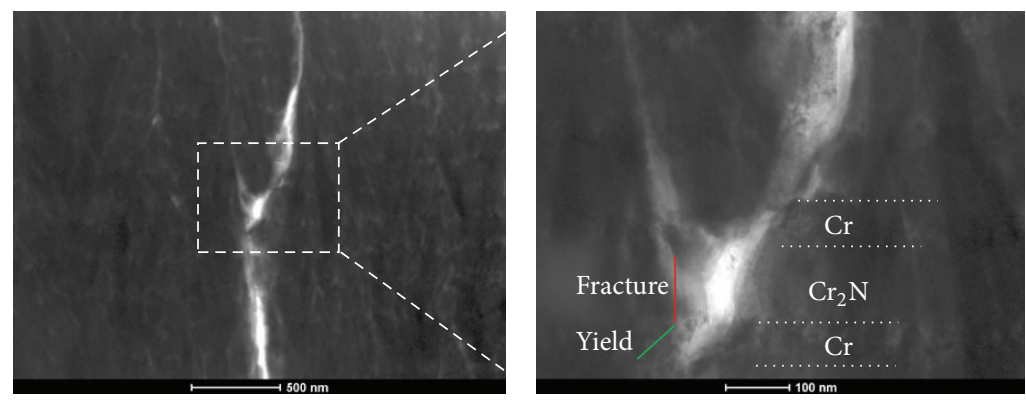

FIGURE 9: TEM images of the deformation mechanism of $\mathrm{Cr} / \mathrm{Cr}_{2} \mathrm{~N}$ multilayers.

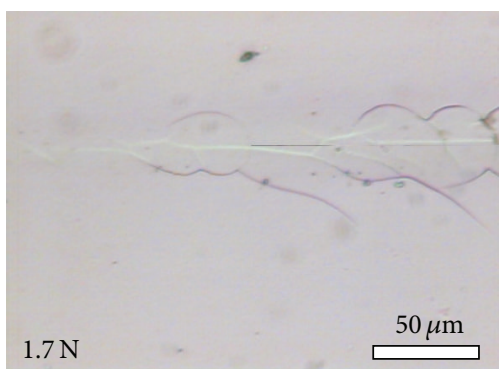

(a)

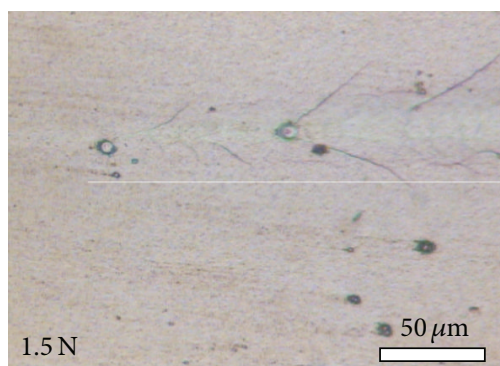

(d)

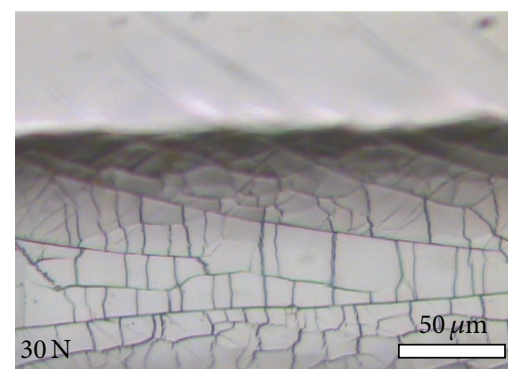

(b)

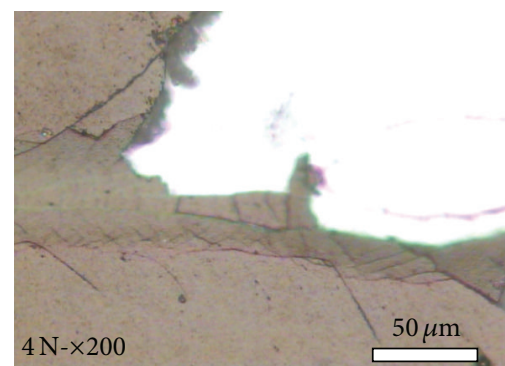

(e)

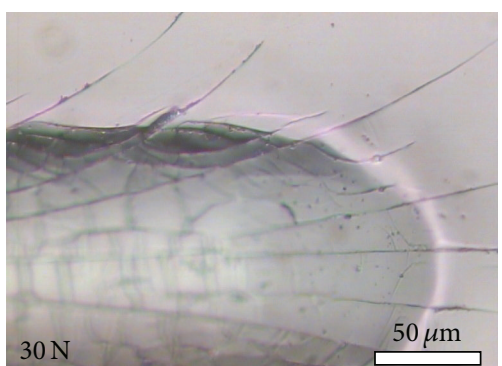

(c)

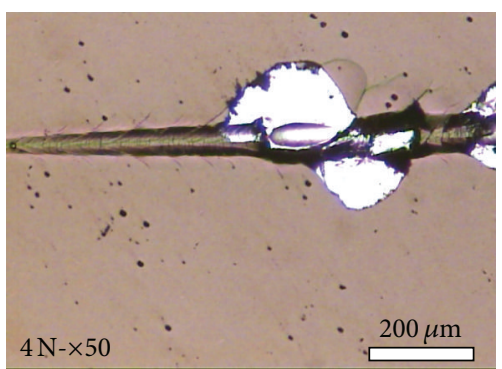

(f)

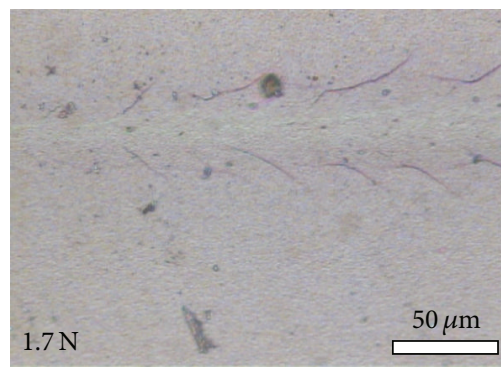

(g)

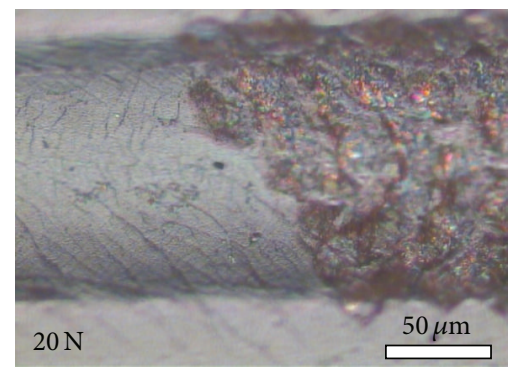

(h)

Figure 10: Scratch track images: (a)-(c) coating A, (d)-(f) coating B, and (g)-(h) coating C.

A different character of failure compared with coatings $\mathrm{A}$ and $\mathrm{B}$ was observed for coating $\mathrm{C}$, which was crushed and removed from the substrate at a $20 \mathrm{~N}$ load. Scratch images indicate that this is a result of exceeding the load capacity of the coating rather than the adhesion lost.

The tribological tests were performed at 1 and $5 \mathrm{~N}$ loads and typical profiles of wear scars are presented in Figures 11(a) and $11(\mathrm{~b})$.

For lower loads, the track depth was always less than $1 \mu \mathrm{m}$ (Figure 11(a)), and therefore only carbon layers were subjected to wear. The shapes of wear track profiles on coatings $A$ and $B$ have no pile-ups on their sides, which suggests that the dominant form of wear was abrasion. Some scratches along the track were formed (Figures 12(a) and 12(c)) as a result of the spallation of small coating fragments, which remained in the friction zone and scratched the surface. In the case of coating $\mathrm{C}$, small pile-ups on the sides of the wear track were formed. Microscopic observation confirmed the accumulation of debris on the outer side of the track (right side in Figure 12(e)). The significantly lower hardness of this 


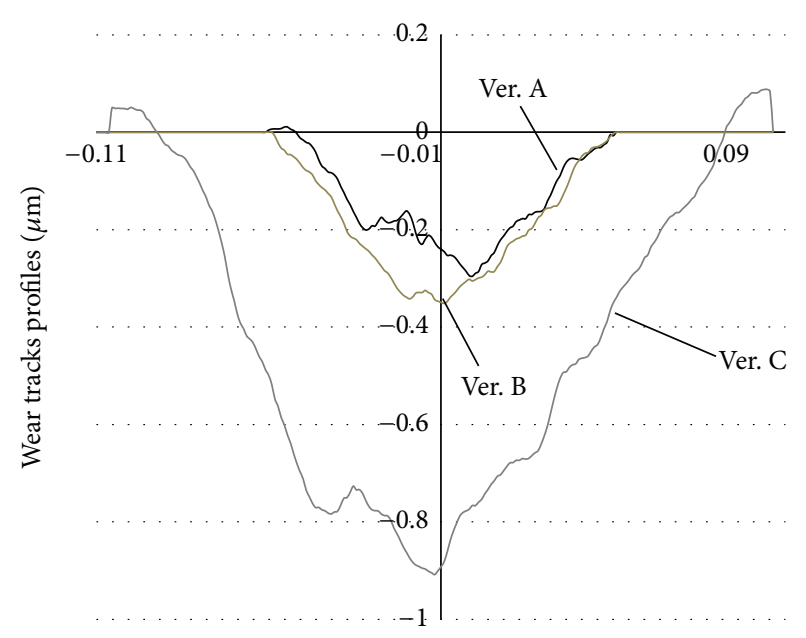

(a)

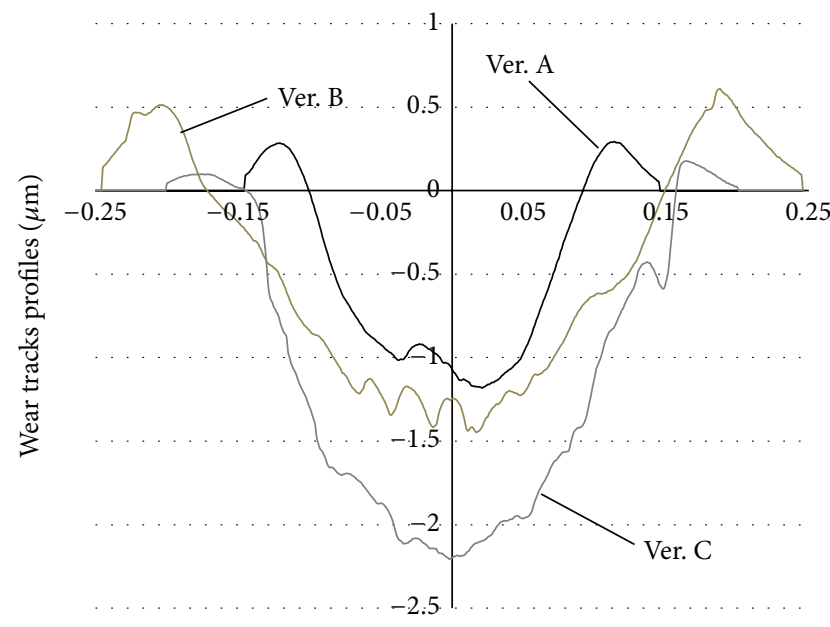

(b)

FIGURE 11: Wear track profiles after tests at (a) $1 \mathrm{~N}$ and (b) $5 \mathrm{~N}$ loads.

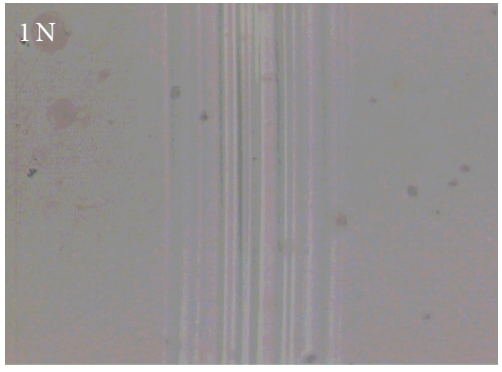

(a)

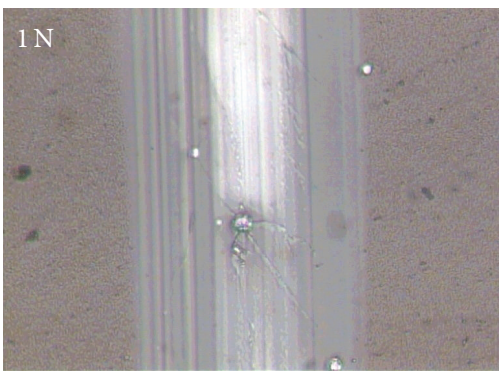

(c)

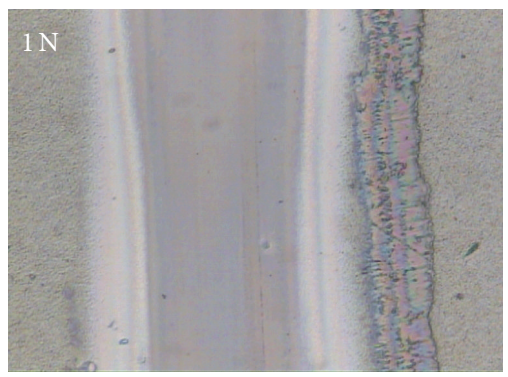

(e)

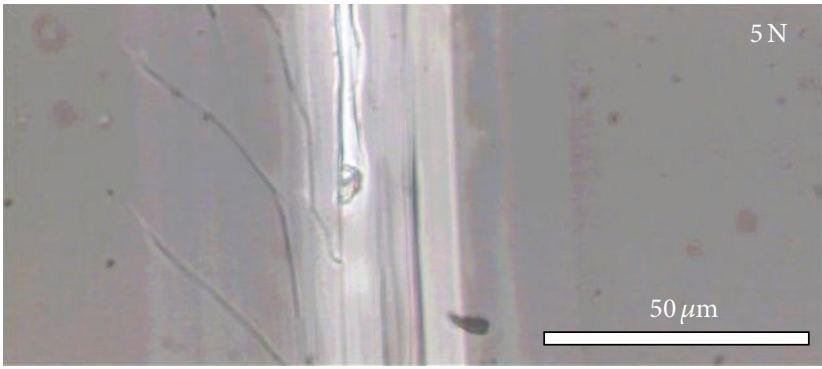

(b)

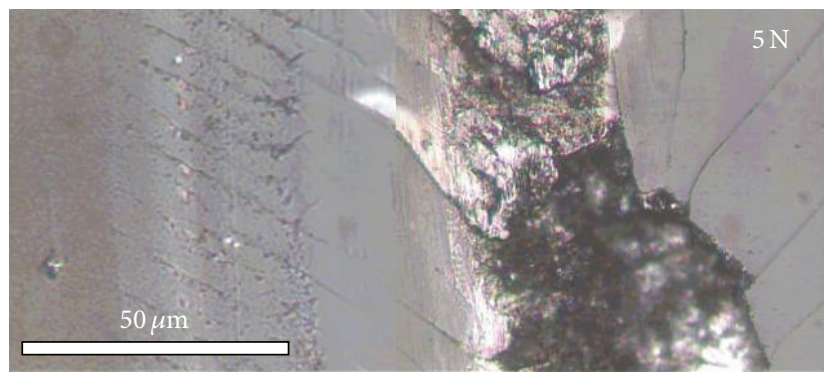

(d)
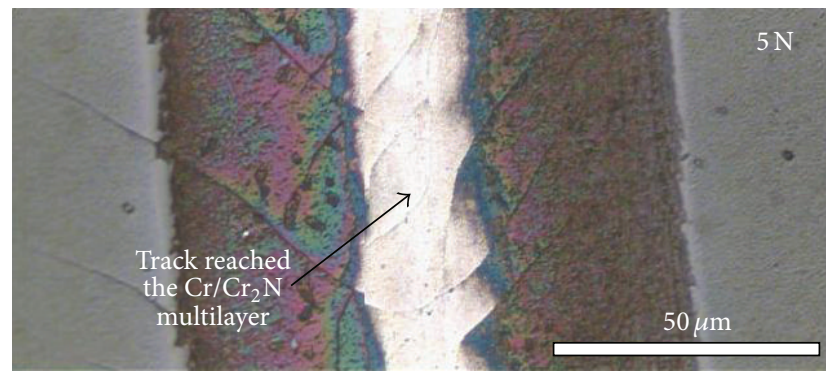

(f)

Figure 12: Images of wear tracks for tested coatings: version A: (a) $1 \mathrm{~N}$ and (b) $5 \mathrm{~N}$ loads; version $\mathrm{B}$ : (c) $1 \mathrm{~N}$ and (d) $5 \mathrm{~N}$ loads; version C: (e) $1 \mathrm{~N}$ and (f) $5 \mathrm{~N}$ loads. 


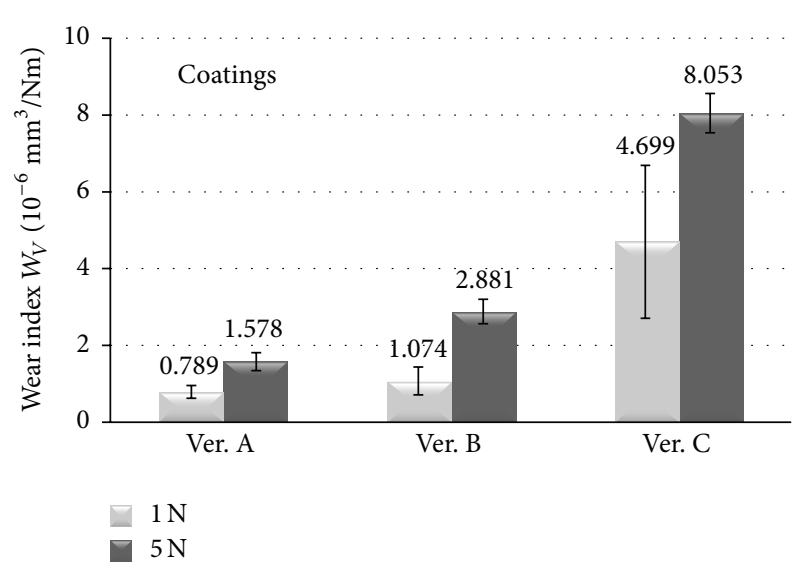

(a)

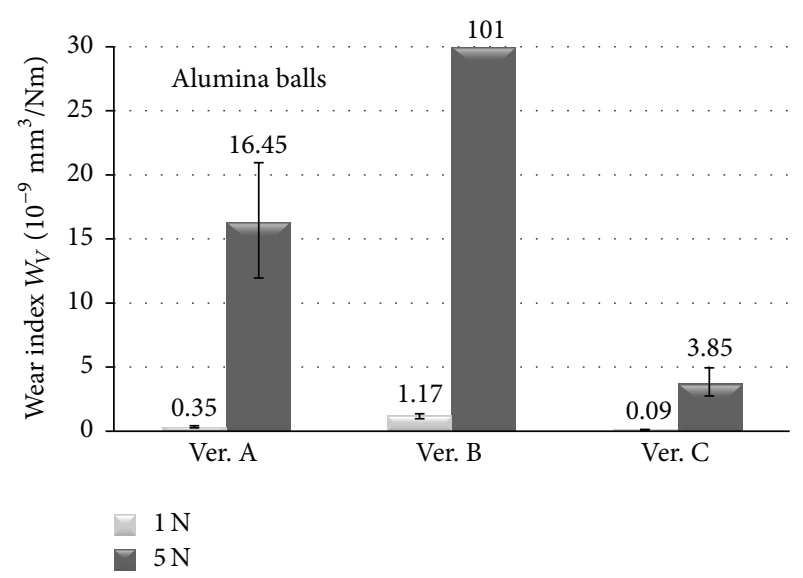

(b)

FIGURE 13: Wear index of tested friction pairs: (a) coatings and (b) balls.

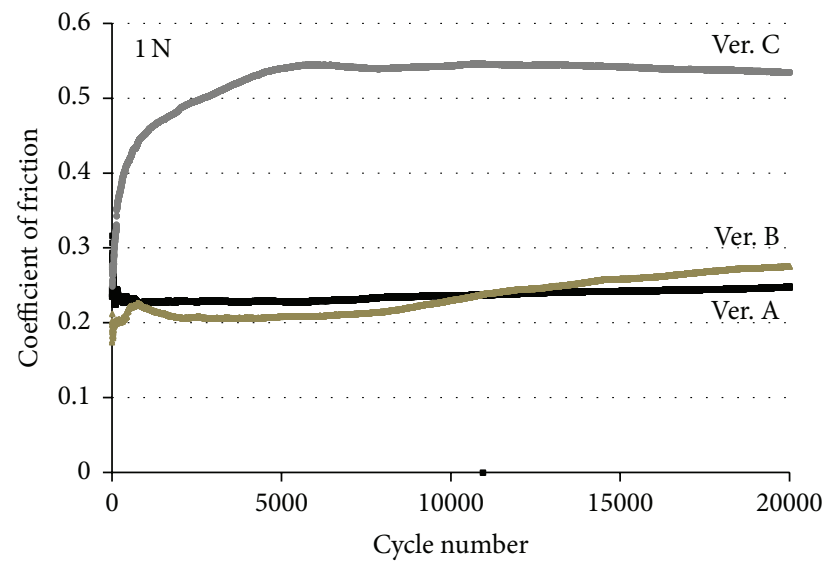

(a)

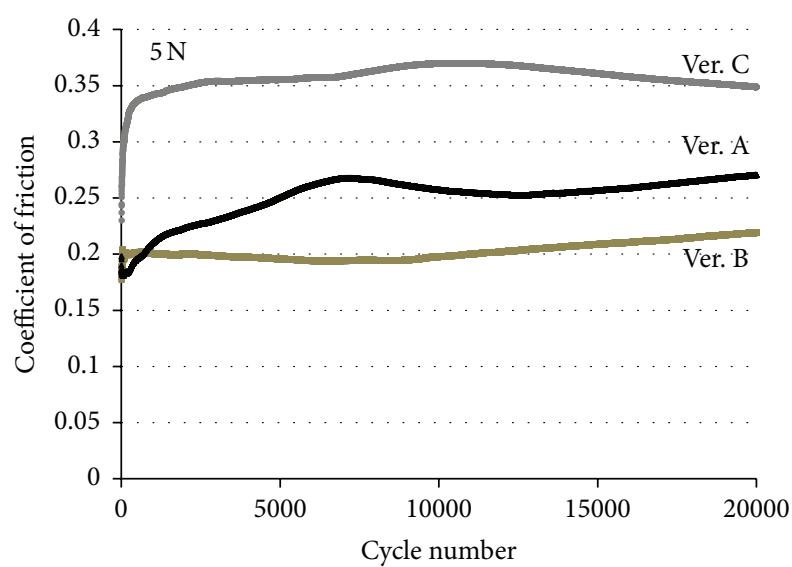

(b)

FIGURE 14: Coefficient of friction changes during tribological tests performed at (a) $1 \mathrm{~N}$ and (b) $5 \mathrm{~N}$ loads.

coating caused more intensive wear and the maximum track depth was $0.9 \mu \mathrm{m}$ compared with $0.3 \mu \mathrm{m}$ for the other two coatings. Thus, the results suggest that the idea of deposition of a very soft outermost layer is not appropriate even in the case of lower load in tribological contact conditions. After the tests were performed at a $5 \mathrm{~N}$ load for all coatings, pile-ups were observed on both sides of the wear tracks, indicating the plastic deformation of substrates. This phenomenon is dangerous due to the increased deformation of the whole system and possible coating fracture. For coating A, the track depth is about $1 \mu \mathrm{m}$, equal to the carbon layer thickness (Figure 11(b)). Meanwhile, for coatings B and C, track depth was deeper and the $\mathrm{Cr} / \mathrm{Cr}_{2} \mathrm{~N}$ multilayers were also involved in the wear process.

High contact pressure in the friction zone, calculated using the Hertz equation, was approximately $0.8 \mathrm{GPa}$ and led to the coatings' strength being exceeded and their fracture. Longitudinal cracks appeared in the wear track mainly close to the symmetry axis, as well as around the track and propagated far beyond it. For coating A, within the test duration, no adhesive cracks were formed (Figure 12(b)), while some small areas of coating spallation and substrate exposure were observed in coating B (Figure 12(d)).

Coating $\mathrm{C}$ was completely worn and, despite its much lower hardness, the crack network was seen inside and around the wear track. Additionally, debris remained on the track sides. Furthermore, this coating (Figure 14) did not reduce the friction coefficient, as it is often observed for carbon coatings, where the graphitization process on the surface reduces $\mathrm{CoF}$ at certain conditions even below 0.1 $[15,52]$.

The values of the wear index $W_{V}$, calculated from wear track profiles and (1), are summarized in Figure 13. At both $1 \mathrm{~N}$ and $5 \mathrm{~N}$ loads, the lowest values of $W_{V}$ were exhibited by coating $\mathrm{A}$. In contrast, the worst was the softest coating C, with a wear index 5-6 times higher than for coating A, in spite of a very similar plasticity index $H / E=0.09-0.11$, which is often cited in the literature $[53,54]$ as a parameter that predicts the wear resistance of materials. For each of the tested materials, the wear index increased 2-3 times with a rise in load up to $5 \mathrm{~N}$ compared with tests carried out at $1 \mathrm{~N}$. This is due to exceeding the limit of elastic deformation 
for the system and changes in the wear mechanism from abrasion to combined abrasion and fracture with chipped fragments of coatings. Comparing the wear rates of versions $\mathrm{A}$ and $\mathrm{B}$ (at $1 \mathrm{~N}$ load), they are similar to the best of the Cr/a$\mathrm{C}: \mathrm{H}, \mathrm{N}$ single coatings included in these advanced coatings and significantly better than the commonly used a-C:H [26, 55-57]. Furthermore, the single carbon coatings were totally destroyed after a few hundred cycles during wear tests at $5 \mathrm{~N}$, while coating A survived the whole test duration. The lower wear of coating A than B was accompanied by the lower wear of alumina balls for both 1 and $5 \mathrm{~N}$ loads, as is shown in Figure 13(b). It is characteristic that the wear index of the balls increased rapidly with the load. For example, the wear of the ball in contact with coating B was over 80 times greater at the $5 \mathrm{~N}$ load than at $1 \mathrm{~N}$. This was due to the presence of hard debris particles, originating from cracked coating fragments (Figure 12(d)), in the friction zone. At the lower load, the wear had a slightly abrasive character and further protection against wear was provided by carbon layers formed on the balls' surfaces, as observed after the tests. The minimal wear of the balls, in the case of tests performed at $1 \mathrm{~N}$, was measured after contact with the softest coating $\mathrm{C}$. The wear of the ball was also the lowest at $5 \mathrm{~N}$. However, the ball was worn within the area of contact with the multilayer, which was exposed during the tests (Figure 12(f)). It should be noted that the wear of the alumina balls was even a few thousand times smaller than the coatings' wear: the values on the axis of ordinates for coatings are in $10^{-6}$ while for balls they are in $10^{-9} \mathrm{~mm}^{3} / \mathrm{Nm}$.

The typical changes in the friction coefficient during the tests (selected tests for each coating) measured at 1 and $5 \mathrm{~N}$ are shown in Figures 14(a) and 14(b), respectively. Coatings A and $\mathrm{B}$ exhibited a $\mathrm{CoF}$ in the $0.2-0.25$ range, higher than for a single a-C:N coating $\mathrm{CoF}=0.1$ (Table 1 ). This is probably due to the fairly rapid destruction of the thin $(200 \mathrm{~nm})$ a-C:N layer at the beginning of the test, when the contact stress is the highest (specific feature of ball-on-disc). Hence, the friction coefficient measured for coatings $\mathrm{A}$ and $\mathrm{B}$ is higher and its value is characteristic for the harder materials lying below a-C:N, like Cr/a-C:H,N and Cr/a-C:H with $\mathrm{CoF}=0.22$ and 0.4 , respectively. Meanwhile, for coating $\mathrm{C}$ this parameter was higher, 0.55 and 0.35 for the test performed at $1 \mathrm{~N}$ and $5 \mathrm{~N}$ loads, respectively. This coating is softer so the deformation component of friction led to an increase in friction force.

\section{Conclusions}

The coatings with complex architecture presented in this work were built by adding load-bearing ceramic/metal multilayers and graded carbon layers deposited on them. Through the appropriate choice of material and thickness of successive layers, the obtained coatings have significantly better fracture resistance than single coatings. However, the hardness of coatings $\mathrm{A}$ and $\mathrm{B}$ of $\mathrm{H}=15 \mathrm{GPa}$ is much lower than for $\mathrm{Cr} / \mathrm{a}$ $\mathrm{C}: \mathrm{H}$ nanocomposite coatings, $18 \mathrm{GPa}$. Meanwhile, the elasticity modulus, $E=160 \mathrm{GPa}$, of the proposed coatings is significantly lower compared with $280 \mathrm{GPa}$, which is characteristic for $\mathrm{Cr} / \mathrm{a}-\mathrm{C}: \mathrm{H}$. The reduction in Young's modulus results in lower contact stresses, which for the same coating strength indicates the possibility of carrying higher loads. This was evident during spherical indentation when coatings $\mathrm{A}$ and $\mathrm{B}$ cracked at 340 and $310 \mathrm{mN}$ loads, almost 3 times higher than a single a-C:H coating. The appropriate deposition on the steel substrate of first the ceramic/metal multilayer and then a graded carbon layer caused a low mismatch of mechanical properties at subsequent layer interfaces. The result is a high fracture resistance of the proposed graded coatings, but also for coating A, very good adhesion to the multilayer, which has been confirmed by scratch testing. From a mechanical point of view, an important role in the whole coating is played by the $\mathrm{Cr} / \mathrm{Cr}_{2} \mathrm{~N}$ multilayer, which allows coating deformations without losing its coherence. The small cracks within the $\mathrm{Cr}_{2} \mathrm{~N}$ layers are closed or deflected in the $\mathrm{Cr}$ metal layers, preventing easy crack propagation throughout the whole coating thickness, as is observed for single ceramic and carbon coatings. In many cases, such cracks after reaching the coating-substrate interface propagate further through this interface, leading to large area coating delamination. Coating $\mathrm{A}$, in addition to high fracture toughness, has shown excellent tribological properties. The wear index is in the range of the best $\mathrm{Cr} / \mathrm{a}-\mathrm{C}: \mathrm{H}, \mathrm{N}$ single coatings. However, a very promising result is at $5 \mathrm{~N}$, when wear resistance indeed is two times lower, but none of the single coatings survived the test at this condition. Unfortunately, the friction coefficient $\mathrm{CoF}=0.2-$ 0.25 of coatings $A$ and $B$ was higher than for a-C:N with a $\mathrm{CoF}$ $=0.1$. Among the tested coatings, the polymer-like coating $\mathrm{C}$ has significantly different properties and was quickly destroyed even at low loads in the tribological contact.

Summarising, properly designed coatings composed of multilayers and graded amorphous carbon layers can exhibit significantly better properties than the single a-C:H and aC:N coatings. Coatings with complex architecture, as presented in this paper, significantly increase fracture resistance and do not deteriorate or may even slightly improve tribological properties, in particular, wear resistance. This indicates the possible applications of the proposed coatings where single coatings cannot fulfil all demands.

\section{Conflict of Interests}

The authors declare that there is no conflict of interests regarding the publication of this paper.

\section{Acknowledgment}

The research project was financed by the National Science Centre (in Polish: Narodowe Centrum Nauki, abbr. NCN) Grant nos. 2012/07/B/ST8/03396 and 2012/06/M/ST8/00408.

\section{References}

[1] D. Jianxin, L. Jianhua, Z. Jinlong, S. Wenlong, and N. Ming, "Friction and wear behaviors of the PVD ZrN coated carbide in sliding wear tests and in machining processes," Wear, vol. 264, no. 3-4, pp. 298-307, 2008.

[2] W. Feng, D. Yan, J. He, X. Li, and Y. Dong, "Reactive plasma sprayed TiN coating and its tribological properties," Wear, vol. 258, no. 5-6, pp. 806-811, 2005. 
[3] J. Lin, W. D. Sproul, and J. J. Moore, "Tribological behavior of thick $\mathrm{CrN}$ coatings deposited by modulated pulsed power magnetron sputtering," Surface and Coatings Technology, vol. 206, no. 8-9, pp. 2474-2483, 2012.

[4] S. Fouvry, B. Wendler, T. Liskiewicz, M. Dudek, and L. Kolodziejczyk, "Fretting wear analysis of TiC/VC multilayered hard coatings: experiments and modelling approaches," Wear, vol. 257, no. 7-8, pp. 641-653, 2004.

[5] Y. Suda, H. Kawasaki, K. Doi, and S. Hiraishi, "Formation and properties of $\mathrm{TiC}$ thin films by pulsed Nd/YAG laser deposition," Thin Solid Films, vol. 374, no. 2, pp. 282-286, 2000.

[6] J. Mateos, J. M. Cuetos, E. Fernández, and R. Vijande, "Tribological behaviour of plasma-sprayed WC coatings with and without laser remelting," Wear, vol. 239, no. 2, pp. 274-281, 2000.

[7] R. Hauert, "An overview on the tribological behavior of diamond-like carbon in technical and medical applications," Tribology International, vol. 37, no. 11-12, pp. 991-1003, 2004.

[8] A. Vanhulsel, F. Velasco, R. Jacobs et al., "DLC solid lubricant coatings on ball bearings for space applications," Tribology International, vol. 40, no. 7, pp. 1186-1194, 2007.

[9] C. Srisang, P. Asanithi, K. Siangchaew, S. Limsuwan, A. Pokaipisit, and P. Limsuwan, "Raman spectroscopy of DLC/a-Si bilayer film prepared by pulsed filtered cathodic arc," Journal of Nanomaterials, vol. 2012, Article ID 745126, 5 pages, 2012.

[10] T. C. S. Vandevelde, K. Vandierendonck, M. Van Stappen, W. Du Mong, and P. Perremans, "Cutting applications of DLC, hard carbon and diamond films," Surface and Coatings Technology, vol. 113, no. 1-2, pp. 80-85, 1999.

[11] W. Precht and A. Czyzniewski, "Deposition and some properties of carbide/amorphous carbon nanocomposites for tribological application," Surface and Coatings Technology, vol. 174-175, pp. 979-983, 2003.

[12] N. Sharma, N. Kumar, S. Dash et al., "Scratch resistance and tribological properties of DLC coatings under dry and lubrication conditions," Tribology International, vol. 56, pp. 129-140, 2012.

[13] M. Sedlaček, B. Podgornik, and J. Vižintin, “Tribological properties of DLC coatings and comparison with test results: development of a database," Materials Characterization, vol. 59, no. 2, pp. 151-161, 2008.

[14] A. Erdemir, "Genesis of superlow friction and wear in diamond like carbon films," Tribology International, vol. 37, no. 11-12, pp. 1005-1012, 2004.

[15] Y. Liu, A. Erdemir, and E. I. Meletis, "An investigation of the relationship between graphitization and frictional behavior of DLC coatings," Surface and Coatings Technology, vol. 86-87, no. 2, pp. 564-568, 1996.

[16] L. Major, M. Janusz, M. Kot, J. M. Lackner, and B. Major, "Development and complex characterization of bio-tribological $\mathrm{Cr} /$ $\mathrm{CrN}+\mathrm{a}-\mathrm{C}: \mathrm{H}$ (doped $\mathrm{Cr}$ ) nano-multilayer protective coatings for carbon-fiber-composite materials," RSC Advances, vol. 5, no. 13, pp. 9405-9415, 2015.

[17] R. Hauert and U. Müller, "An overview on tailored tribological and biological behavior of diamond-like carbon," Diamond and Related Materials, vol. 12, no. 2, pp. 171-177, 2003.

[18] Z.-H. Xie, R. Singh, A. Bendavid, P. J. Martin, P. R. Munroe, and M. Hoffman, "Contact damage evolution in a diamond-like carbon (DLC) coating on a stainless steel substrate," Thin Solid Films, vol. 515, no. 6, pp. 3196-3201, 2007.

[19] A. Rousseau, J. G. Partridge, E. L. H. Mayes et al., "Microstructural and tribological characterisation of a nitriding/TiAlN PVD coating duplex treatment applied to M2 High Speed Steel tools," Surface and Coatings Technology, vol. 272, pp. 403-408, 2015.

[20] E. Skolek-Stefaniszyn, J. Kamiński, J. Sobczak, and T. Wierzchon, "Modifying the properties of AISI 316L steel by glow discharge assisted low-temperature nitriding and oxynitriding," Vacuum, vol. 85, no. 2, pp. 164-169, 2010.

[21] Z. Xie, Z. Luo, Q. Yang et al., "Improving anti-wear and anticorrosion properties of AM60 magnesium alloy by ion implantation and $\mathrm{Al} / \mathrm{AlN} / \mathrm{CrAlN} / \mathrm{CrN} / \mathrm{MoS}_{2}$ gradient duplex coating," Vacuum, vol. 101, pp. 171-176, 2014.

[22] D. Kakaš, B. Škoric, and M. Rakita, "Tribological behavior of duplex coating improved by ion implantation," Thin Solid Films, vol. 459, no. 1-2, pp. 152-155, 2004.

[23] X. C. Zhang, B. S. Xu, H. D. Wang, Y. X. Wu, and Y. Jiang, "Hertzian contact response of single-layer, functionally graded and sandwich coatings," Materials and Design, vol. 28, no. 1, pp. 47-54, 2007.

[24] J. L. He, K. C. Chen, and A. Davison, "Improvements in the understanding and application of duplex coating systems using arc plasma technology," Surface and Coatings Technology, vol. 200, no. 5-6, pp. 1464-1471, 2005.

[25] M. Kot, W. A. Rakowski, Ł. Major, R. Major, and J. Morgiel, "Effect of bilayer period on properties of $\mathrm{Cr} / \mathrm{CrN}$ multilayer coatings produced by laser ablation," Surface and Coatings Technology, vol. 202, no. 15, pp. 3501-3506, 2008.

[26] M. Kot, K. Przywara-Chronowska, W. Rakowski, J. Lackner, W. Waldhauser, and $€$. Major, "The advantages of incorporating $\mathrm{Cr}_{x} \mathrm{C}$ nanograins into an a-C:H matrix in tribological coatings," Materials and Design, vol. 56, pp. 981-989, 2014.

[27] M. Kot, Ł. Major, and J. Lackner, "The tribological phenomena of a new type of TiN/a-C:H multilayer coatings," Materials \& Design, vol. 51, pp. 280-286, 2013.

[28] J. M. Lackner, Ł. Major, and M. Kot, "Microscale interpretation of tribological phenomena in Ti/TiN soft-hard multilayer coatings on soft austenite steel substrates," Bulletin of the Polish Academy of Sciences: Technical Sciences, vol. 59, no. 3, pp. 343356, 2011.

[29] Z. G. Wu, G. A. Zhang, M. X. Wang, X. Y. Fan, P. X. Yan, and T. $\mathrm{Xu}$, "Structure and mechanical properties of Al/AlN multilayer with different AlN layer thickness," Applied Surface Science, vol. 253, no. 5, pp. 2733-2738, 2006.

[30] ISO, "Fine ceramics (advanced ceramics, advanced technical ceramics) - determination of adhesion of ceramic coatings by scratch testing," ISO 20502, 2005.

[31] G. S. Was and T. Foecke, "Deformation and fracture in microlaminates," Thin Solid Films, vol. 286, no. 1-2, pp. 1-31, 1996.

[32] M. Kot, "Contact mechanics of coating-substrate systems: monolayer and multilayer coatings," Archives of Civil and Mechanical Engineering, vol. 12, no. 4, pp. 464-470, 2012.

[33] L. Yate, L. Martínez-de-Olcoz, J. Esteve, and A. Lousa, "Effect of the bias voltage on the structure of nc-CrC/a-C:H coatings with high carbon content," Surface and Coatings Technology, vol. 206, no. 11-12, pp. 2877-2883, 2012.

[34] E. L. Dalibón, D. Heim, C. Forsich, A. Rosenkranz, M. Agustina Guitar, and S. P. Brühl, "Characterization of thick and soft DLC coatings deposited on plasma nitrided austenitic stainless steel," Diamond and Related Materials, vol. 59, pp. 73-79, 2015.

[35] ISO, "Metallic materials-instrumented indentation test for hardness and material parameters-part 1: test method," ISO 14577-1, International Organization for Standardization, London, UK, 2015. 
[36] A. C. Fischer-Cripps, "Critical review of analysis and interpretation of nanoindentation test data," Surface and Coatings Technology, vol. 200, no. 14-15, pp. 4153-4165, 2006.

[37] W. C. Oliver and G. M. Pharr, "An improved technique for determining hardness and elastic modulus using load and displacement sensing indentation experiments," Journal of Materials Research, vol. 7, no. 6, pp. 1564-1580, 1992.

[38] X. Li and B. Bhushan, "Measurement of fracture toughness of ultra-thin amorphous carbon films," Thin Solid Films, vol. 315, no. 1-2, pp. 214-221, 1998.

[39] J. Malzbender and G. de With, "The use of the indentation loading curve to detect fracture of coatings," Surface and Coatings Technology, vol. 137, no. 1, pp. 72-76, 2001.

[40] E. Martínez, J. Romero, A. Lousa, and J. Esteve, "Nanoindentation stress-strain curves as a method for thin-film complete mechanical characterization: application to nanometric CrN/Cr multilayer coatings," Applied Physics A, vol. 77, no. 34, pp. 419-426, 2003.

[41] S. J. Bull and E. G. Berasetegui, "An overview of the potential of quantitative coating adhesion measurement by scratch testing," Tribology International, vol. 39, no. 2, pp. 99-114, 2006.

[42] ISO, "Fine ceramics (advanced ceramics, advanced technical ceramics)-determination of friction and wear characteristics of monolithic ceramics by ball-on-disc method," ISO 20808, 2004.

[43] H. Hertz, Miscellaneous Papers, Jones and Schott, Macmillan, London, UK, 1863.

[44] K. L. Johnson, Contact Mechanics, Cambridge University Press, Cambridge, UK, 1985.

[45] R. Saha and W. D. Nix, "Effects of the substrate on the determination of thin film mechanical properties by nanoindentation," Acta Materialia, vol. 50, no. 1, pp. 23-38, 2002.

[46] A. Czyzniewski, "Preparation and characterisation of a-C and a-C:H coatings deposited by pulsed magnetron sputtering," Surface and Coatings Technology, vol. 203, no. 8, pp. 1027-1033, 2009.

[47] T. Pachler, R. M. Souza, and A. P. Tschiptschin, "Finite element analysis of peak stresses developed during indentation of ceramic coated steels," Surface and Coatings Technology, vol. 202, no. 4-7, pp. 1098-1102, 2007.

[48] J. Michler and E. Blank, "Analysis of coating fracture and substrate plasticity induced by spherical indentors: diamond and diamond-like carbon layers on steel substrates," Thin Solid Films, vol. 381, no. 1, pp. 119-134, 2001.

[49] M. Kot, J. M. Lackner, Ł. Major, and W. Rakowski, "Analysis of spherical indentations of coating-substrate systems: experiments and finite element modeling," Materials and Design, vol. 43, pp. 99-111, 2013.

[50] P. Wang, X. Wang, T. Xu, W. Liu, and J. Zhang, "Comparing internal stress in diamond-like carbon films with different structure," Thin Solid Films, vol. 515, no. 17, pp. 6899-6903, 2007.

[51] M. Kot, Ł. Major, W. Rakowski, and J. M. Lackner, "Enhancement of mechanical and tribological properties of Ti/TiN multilayers over TiN single layer," Journal of the Balkan Tribological Association, vol. 18, no. 1, pp. 92-105, 2012.

[52] T. Vitu, A. Escudeiro, T. Polcar, and A. Cavaleiro, "Sliding properties of Zr-DLC coatings: the effect of tribolayer formation," Surface and Coatings Technology, vol. 258, pp. 734-745, 2014.

[53] J. C. A. Batista, C. Godoy, G. Pintaúde, A. Sinatora, and A. Matthews, "An approach to elucidate the different response of PVD coatings in different tribological tests," Surface and Coatings Technology, vol. 174-175, pp. 891-898, 2003.
[54] A. Leyland and A. Matthews, "On the significance of the $H / E$ ratio in wear control: a nanocomposite coating approach to optimised tribological behaviour," Wear, vol. 246, no. 1-2, pp. $1-11,2000$.

[55] S. Zimowski, T. Moskalewicz, M. Kot, B. Wendler, and A. Czyrska-Filemonowicz, "Microstructure, mechanical and tribological properties of the nc- $\mathrm{Cr}_{x} \mathrm{C}_{y} / \mathrm{a}-\mathrm{C}$ and nc- $\mathrm{Cr}_{x} \mathrm{C}_{y} / \mathrm{a}-\mathrm{C}: \mathrm{H}$ nanocomposite coatings on oxygen-hardened Ti-6Al-4V alloy," Surface and Interface Analysis, vol. 44, no. 8, pp. 1225-1228, 2012.

[56] J. Patscheider, T. Zehnder, and M. Diserens, "Structure-performance relations in nanocomposite coatings," Surface and Coatings Technology, vol. 146-147, pp. 201-208, 2001.

[57] R. Gåhlin, M. Larsson, and P. Hedenqvist, "ME-C:H coatings in motor vehicles," Wear, vol. 249, no. 3-4, pp. 302-309, 2001. 

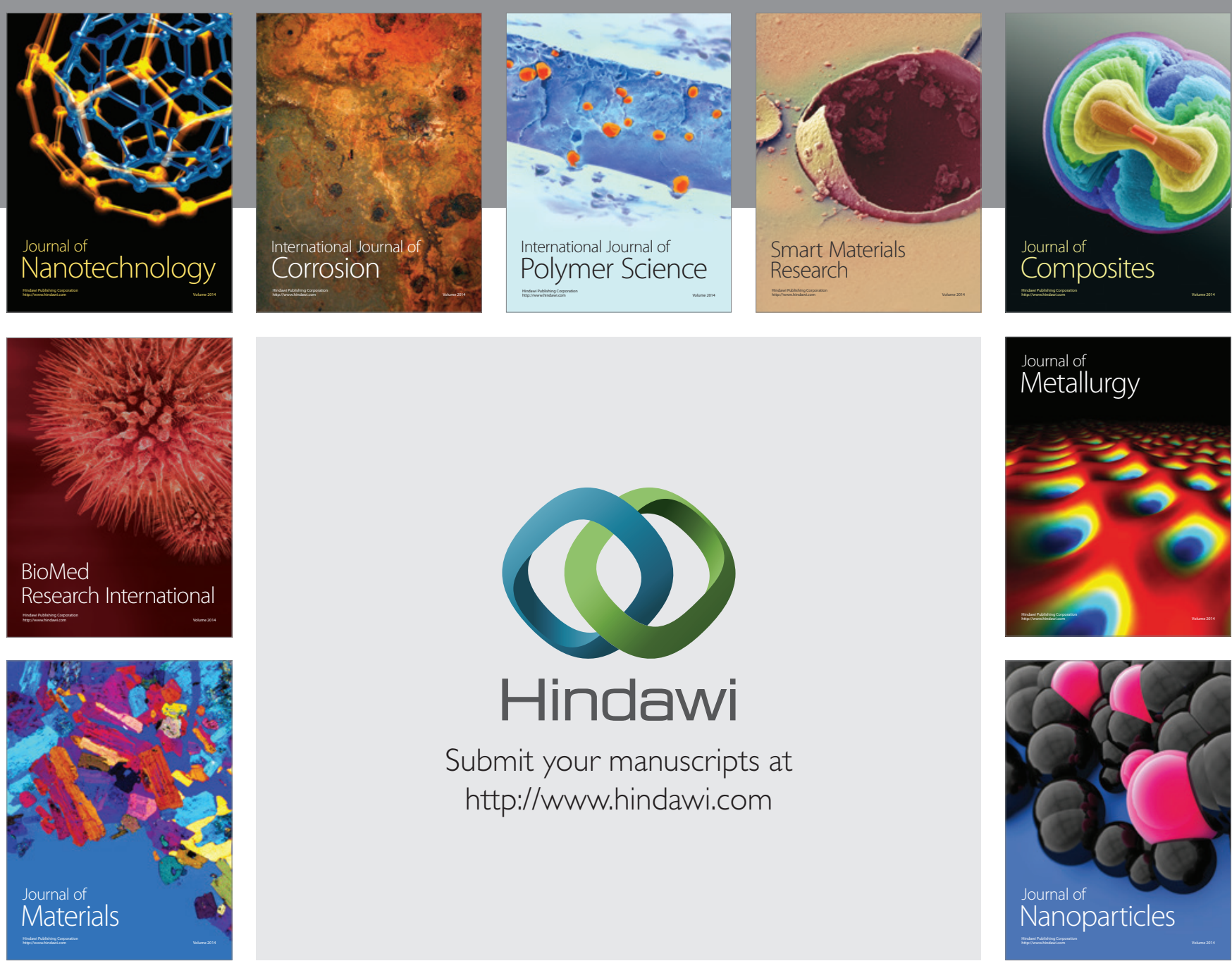

\section{Hindawi}

Submit your manuscripts at

http://www.hindawi.com

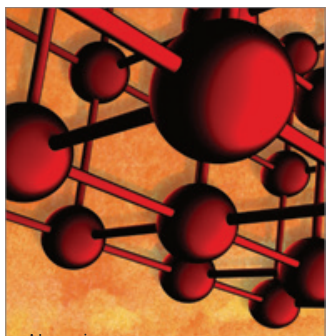

Materials Science and Engineering
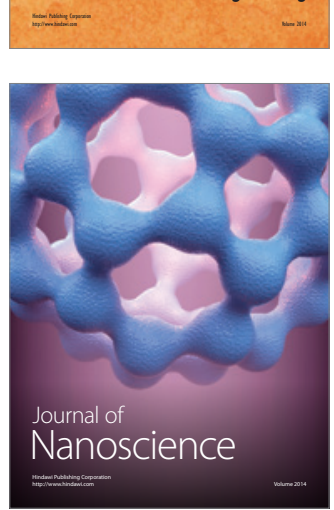
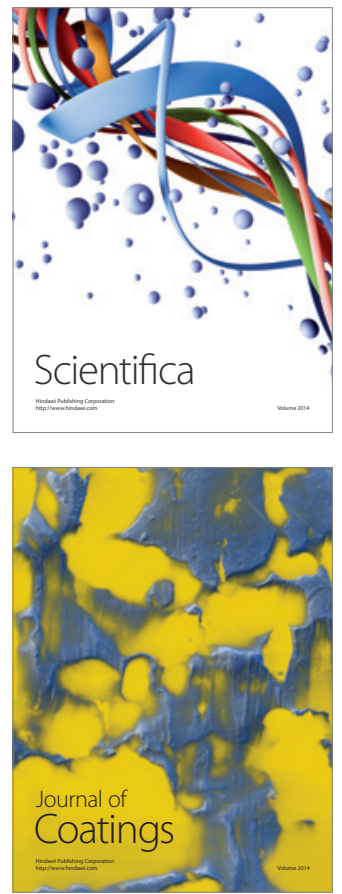
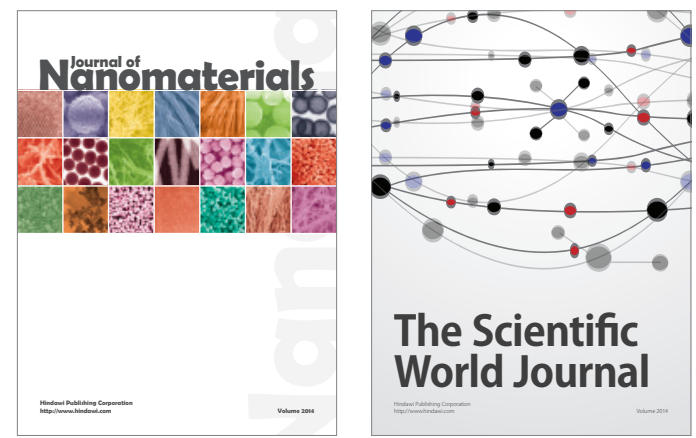

The Scientific World Journal
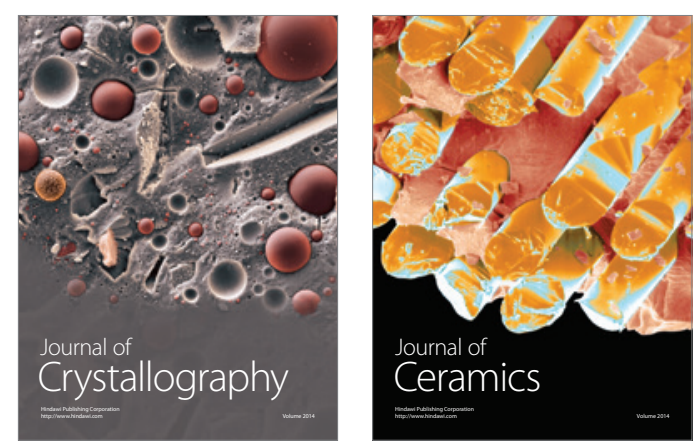
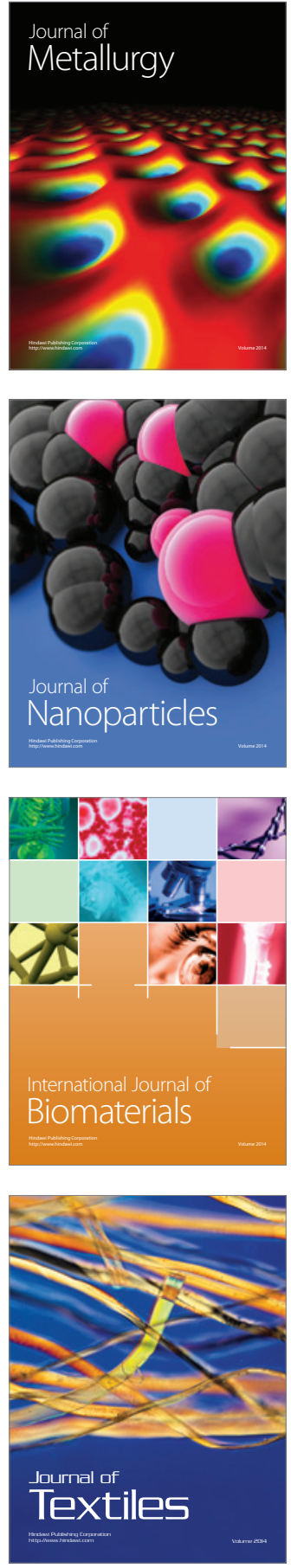